\title{
The Turn of the Century North American Drought: Global Context, Dynamics, and Past Analogs*
}

\author{
RICHARD SEAGER \\ Lamont-Doherty Earth Observatory, Columbia University, Palisades, New York
}

(Manuscript received 7 June 2006, in final form 6 March 2007)

\begin{abstract}
The causes and global context of the North American drought between 1998 and 2004 are examined using atmospheric reanalyses and ensembles of atmosphere model simulations variously forced by global SSTs or tropical Pacific SSTs alone. The drought divides into two distinct time intervals. Between 1998 and 2002 it coincided with a persistent La Niña-like state in the tropical Pacific, a cool tropical troposphere, polewardshifted jet streams, and, in the zonal mean, eddy-driven descent in midlatitudes. During the winters reduced precipitation over North America in the climate models was sustained by anomalous subsidence and reductions of moisture convergence by the stationary flow and transient eddies. During the summers reductions of evaporation and mean flow moisture convergence drove the precipitation reduction, while transient eddies acted diffusively to oppose this. During these years the North American drought fitted into a global pattern of circulation and hydroclimate anomalies with noticeable zonal and hemispheric symmetry.

During the later period of the drought, from 2002 to 2004, weak El Niño conditions prevailed and, while the global climate adjusted accordingly, western North America remained, uniquely among midlatitude regions, in drought. The ensemble mean of the climate model simulations did not simulate the continuation of the drought in these years, suggesting that the termination of the drought was largely unpredictable in terms of global ocean conditions.

The global context of the most recent, turn of the century, drought is compared to the five prior persistent North American droughts in the instrumental record from the mid-nineteenth century on. A classic La Niña pattern of ocean temperature in the Pacific is common to all. A cold Indian Ocean, also typical of La Niña, is common to all five prior droughts, but not the most recent one. Except in southern South America the global pattern of precipitation anomalies of the turn of the century drought is similar to that during the five prior droughts. These comparisons suggest that the earlier period of this most recent drought is the latest in a series of multiyear droughts forced by persistent changes in tropical Pacific Ocean temperatures. Warm tropical North Atlantic Ocean temperatures may play a secondary role.
\end{abstract}

\section{Introduction}

After the 1997-98 El Niño, drought struck across almost the entire United States, northern Mexico, and the Canadian Prairies. At its most severe, between 1999 and 2002, drought stretched from the Pacific Ocean to

* Lamont-Doherty Earth Observatory Contribution Number 7080

Corresponding author address: Richard Seager, LamontDoherty Earth Observatory, Columbia University, Palisades, NY 10964.

E-mail: seager@1deo.columbia.edu the Atlantic Ocean causing forest fires in the American Southwest and Quebec and causing widespread alarm about water resources, even in New York City. The drought ended in eastern North America in the fall of 2002 but continued farther west. In the winter of 2004/ 05 the American Southwest was deluged by rain and snow, but drought persisted farther north in the states and provinces along the Canada/U.S. border. Drought returned to the Southern Plains and the Southwest at the end of 2005. This "turn of the century" drought may not yet be over.

In recent years climate modeling has begun to reveal the causes of North American droughts. Persistent reduced precipitation across the American West occurs during times when the tropical Pacific Ocean is anoma-

DOI: 10.1175/2007JCLI1529.1

(C) 2007 American Meteorological Society 
lously cold, a La Niña-like state. ${ }^{1}$ This has long been recognized on the seasonal to interannual scale, and general circulation models (GCMs) have been able to simulate short droughts as a response to imposed sea surface temperature (SST) anomalies (Mo et al. 1991; Trenberth and Branstator 1992; Atlas et al. 1993; Trenberth and Guillemot 1996; Sud et al. 2003) with tropical SSTs being indicated as most important. On the multiyear time scale, Schubert et al. (2004a) demonstrated that tropical SST anomalies forced drought conditions during the Dust Bowl. Seager et al. (2005b, hereafter S05b) demonstrated, using the Community Climate Model version 3 (CCM3) of the National Center for Atmospheric Research (NCAR), that the Dust Bowl and the 1950s droughts, as well as the wet 1990s, were at least partially forced by tropical Pacific SST anomalies. Huang et al. (2005) have used the same model to attribute multidecadal differences in precipitation throughout the Americas to the 1976-77 tropical Pacific climate shift. Finally, Herweijer et al. (2006, hereafter H06) have used the same model to argue that three severe droughts in the western United States in the mid to late nineteenth century were forced by concurrent persistent La Niña-like states (see also Cook et al. 2007). One of these droughts, the 1856 to 1865 "Civil War" drought, appears to have been the most severe drought in the West since European settlement (Stahle and Cleaveland 1988).

Hoerling and Kumar (2003) specifically showed that, within a multimodel ensemble, the most recent drought was caused by tropical SST variations with both a cold Pacific and warm waters in the Indian Ocean and west Pacific being responsible. Lau et al. $(2005,2006)$ also showed that tropical Indo-Pacific SST anomalies can generate summer drought over North America. All of these model studies agree that tropical Pacific SST anomalies are important for drought generation in the midlatitudes but, to varying degrees, disagree on the relative roles of Pacific, Indian, and Atlantic SST anomalies. In keeping with the idea of an important tropical Pacific role, the return of drought to the southern plains and the Southwest in winter 2005/06 went along with a return of La Niña conditions.

North American droughts fit into a global pattern of

\footnotetext{
${ }^{1}$ The term "La Niña-like" will be used to describe a cold state of the eastern and central tropical Pacific Ocean on the time scale of a few years to a decade (Zhang et al. 1997). This term is preferred over Pacific decadal oscillation (Mantua et al. 1997) because the latter is defined on North Pacific variables, while the decadal variability of SST is clearly hemispherically symmetric (see Zhang et al. 1997; Garreaud and Battisti 1999) and conceivably has a tropical origin (Seager et al. 2004; Newman 2007)
}

hydroclimatic variations. Hoerling and Kumar (2003) note that the most recent drought stretched from west of North America, across the Atlantic Ocean, through the Mediterranean, and into central Asia and S05b have drawn attention to the hemispheric symmetry. The zonal and hemispheric symmetry of precipitation variability has been explained, with reference to interannual El Niño-Southern Oscillation (ENSO) variability, by Seager et al. (2005a, hereafter S05a) in terms of interactions between tropical SSTs, the subtropical jets, the propagation of transient eddies, and the subsequent impact on the eddy-driven mean meridional circulation (MMC) (Seager et al. 2003, hereafter S03). Lau et al. (2006) have also noted the symmetry and offered an explanation in terms of transient eddy-mean flow interactions. According to S05b, the persistent droughts and pluvials are simply low frequency realizations of the same process that they identified on interannual time scales.

In the current paper we expand on these advances in our knowledge of the causes of midlatitude drought by examining in more detail the most recent, turn of the century, drought. We will address the following questions:

1) Does the recent drought fit into the same global pattern of oceanic forcing and circulation and precipitation response as prior persistent droughts?

2) To what extent was the turn of the century drought driven by tropical Pacific SSTs? What is the role of SST anomalies in other basins?

3) What are the details of the atmospheric circulation, moisture transport, subsidence, and surface evaporation anomalies responsible for the most recent drought over North America?

To address these questions we will investigate the precipitation reduction during the drought using satellite and gauge data, atmospheric reanalyses, and ensembles of climate model simulations that cover the period from January 1856 to April 2005. The model simulations variously use global SST anomalies or tropical Pacific SST anomalies only. Although a definition of drought that is of use to water resource users must account for surface and groundwater hydrological processes, the focus here is on a necessary first step in the development of drought: a reduction in precipitation and in precipitation minus evaporation, the net flux of water at the surface available for development as a resource.

This paper builds on analyses and model simulations of tropical forcing of precipitation variability and North American droughts (S05a; S05b; Huang et al. 2005; 
H06; Cook et al. 2007), all of which use the basic dynamics of tropical forcing of hemispherically and zonally symmetric variability covered in S03. Here we apply these ideas to the most recent persistent drought, a period for which, unlike the prior droughts, we have reanalysis data for verification. Readers are referred to the prior papers for more details of the simulations described here, analyses of simulations of earlier droughts, and further discussion of the mechanisms involved.

The data and models are described in the next section. Section 3 examines the model simulation of North American precipitation over the 1979 to 2004 period. Section 4 examines the global context of the drought and section 5 examines the zonal mean anomalies over the 1998 to 2004 period. Section 6 examines the circulation and moisture budget anomalies over North America. Section 7 compares the global context of the most recent drought with that of the five prior multiyear droughts in the instrumental record, and the conclusions follow.

\section{Data and models used in this study}

\section{a. Precipitation data}

We use the combined satellite-gauge precipitation data provided by the Global Precipitation Climatology Project (GPCP: Huffman et al. 1997), which cover the period from January 1979 to April 2005. For the longer perspective we use the gauge data contained within the Global Historical Climatology Network (GHCN), which is based on station data. The coverage is poor over North America in the nineteenth century and this dataset also contains little data over Canada after 1990.

\section{b. Atmospheric circulation data}

To analyze the dynamical context of the drought we use the National Centers for Environmental Prediction (NCEP)-NCAR reanalysis data (Kalnay et al. 1996; Kistler et al. 2001). Temperatures, winds, vertical velocity, eddy transports, geopotential heights, and specific humidity are used. We do not analyze the precipitation reported by the reanalysis, which is unconstrained by precipitation measurements, can have significant errors introduced by NCEP model biases (Kalnay et al. 1996), and need not be in balance with the moisture transports and evaporation within the model (see below). Only reanalysis data from 1979 to 2005 is used, consistent with the time period of satellitebased precipitation estimates, and, in general, only including the portion of the reanalysis that assimilates satellite data.

\section{c. Climate model simulations}

We use the CCM3 (Kiehl et al. 1998) for the climate model simulations as in previous studies of North American droughts (S05a; Huang et al. 2005; H06; $\mathrm{S} 05 \mathrm{~b}$ ). Two configurations are used.

1) POGA-ML: In this case tropical Pacific SSTs are specified $\left(20^{\circ} \mathrm{S}-20^{\circ} \mathrm{N}\right)$ and SSTs elsewhere are computed with a two-layer entraining mixed layer model (Russell et al. 1985) with a specified, seasonally varying, climatological mixed layer depth. A specified "Q flux" accounts for the neglected ocean heat transport and maintains the layer temperatures the same as observed climatology. Between $20^{\circ}$ and $30^{\circ}$ latitude the atmosphere model sees a SST that is a weighted combination of the observed SST and the SST modeled at that point, with the weighting favoring the mixed layer model SST with increasing latitude.

2) GOGA: In this case SSTs are specified globally.

The SST data used comes from two sources of ship and satellite observations. The Kaplan et al. (1998) data is used for the tropical Pacific for the entire period from January 1856 to April 2005. Elsewhere the Hadley Centre Coupled Sea Ice and SST data (HadISST: Rayner et al. 2003) is used. Since the HadISST data begins in 1870, for the GOGA simulations during the period from 1856 to 1870, and outside the tropical Pacific, Kaplan data is used where available and HadISST climatological values where not. For each of the simulations we used 16-member ensembles where each ensemble member used different atmospheric initial conditions on 1 January 1856 and each is run through April 2005. Here we primarily examine the ensemble mean, which isolates the variability forced by the imposed SSTs (either tropical Pacific or global). The ability of the NCAR CCM3 model to simulate prolonged North American droughts has been presented in prior papers (S05b; H06; Huang et al. 2005; Cook et al. 2007).

\section{d. Model-data comparisons}

Throughout the paper model simulations are compared with reanalyses. In related work on interannual ENSO-forced variability it was shown that the moisture budget within the reanalysis, and the derived precipitation it implied, was reasonably consistent with satellitederived estimates of precipitation (S05a). The current work concerns persistent, multiyear variability, a signal that is considerably weaker and which we expect the reanalysis to capture with less fidelity. This is because the longer averaging period will emphasize both prob- 

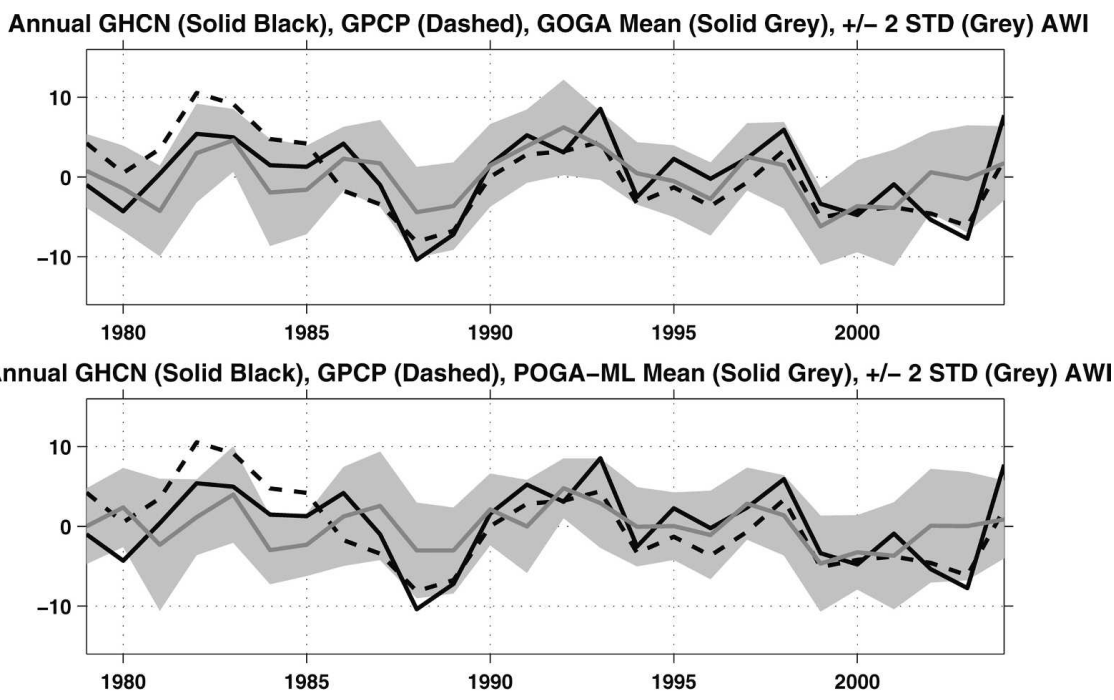

FIG. 1. The annual mean precipitation over the American West $\left(25^{\circ}-50^{\circ} \mathrm{N}, 125^{\circ}-90^{\circ} \mathrm{W}\right)$ for (top) the observed estimates of GHCN and GPCP and the GOGA model forced with global observed SSTs and (bottom) the same observational estimates and the POGA-ML model forced only with tropical Pacific SSTs and with SSTs computed elsewhere with a mixed layer ocean. The shaded area is the plus and minus two standard deviation spread, in each year, of the precipitation in the model ensemble. The precipitation is in $\mathrm{mm}$ month $^{-1}$.

lems with the computation of the moisture budget and biases in the reanalysis. Computation of the moisture budget is problematic because we are working with gridded, pressure level data, not data on the original grid of the NCEP model, and errors are introduced by regridding and choice of numerical methods. In addition, in terms of drought over North America, a leading cause of error within the reanalysis moisture budget is likely to be representation of the atmospheric state over complex topography, especially the vertical motion fields, which are closely linked to precipitation. We did confirm that the derived precipitation captures major interannual precipitation anomalies (e.g., the winter deluge of $1997 / 98$, the wet summer of 1993, and the summer drought of 1988) and closely resembled the satellite estimates and the GHCN data. No such resemblance occurs for the much smaller multiyear variations examined here. Because of these problems we do not present here the terms of the NCEP moisture budget nor the NCEP-derived precipitation.

Quantities other than those related to atmospheric moisture taken, or computed, from the reanalysis are presented throughout the paper alongside modeled anomalies. All should be treated with caution and not as truth, although they will be referred to as "observations."

Given that we will be comparing model ensemble means, which isolate the SST-forced signal, with nature, which includes internal atmospheric variability, we expect some disagreement. The extent to which there is agreement is a measure of predictability of the atmospheric anomalies. There will also be disagreements introduced by systematic errors within the model. Here our goal is limited to a "broad brush" assessment of whether the drought can be attributed to SST forcing and to examine the atmospheric dynamics involved.

\section{Modeled and observed interannual variability of North American precipitation over the 1979-2004 period}

\section{a. Assessing the models ability to simulate interannual variability of precipitation over the} American West

To set the context for the study of the 1998-2004 drought we first present some results pertaining to the year-to-year variability of North American precipitation over the post-1979 period, and its global context, in both observations and the models. In Fig. 1 we show the GPCP satellite-derived precipitation as well as precipitation from rain gauge recordings $(\mathrm{GHCN})$ together with that from the GOGA model (top panel) and that from the POGA-ML model (bottom panel) averaged into annual means over the American West, defined as $25^{\circ}-50^{\circ} \mathrm{N}, 120^{\circ}-90^{\circ} \mathrm{W}$ for the 1979 through 2004 period. 
The shaded area is the plus and minus two standard deviation spread within the model ensemble. ${ }^{2}$

Both modeled and observed precipitation is high during the El Niño years of 1982-83, 1986-87, and 1997-98 and during the years of weak extended El Niño in the early 1990s. Dry conditions were modeled and observed during the La Niña of the 1988-89 period, although the observed precipitation is right at the dry edge of the model ensemble spread. Modeled and observed dry conditions returned in 1998 and persisted in observations through 2004, while the ensemble-mean modeled drought ended in 2002. However, one quarter of the ensemble members had lower than normal precipitation that extended continuously from 1998 through 2004, presumably with the last years arising as a result of natural variability. The model-data comparison suggests that the model is capturing important aspects of tropical Pacific SST-forced precipitation variability over North America. Indeed, in only a few years is the observed precipitation outside of the ensemble spread; that is, a mix of SST-forcing (that is captured by the model) and internal variability can adequately account for the observed history.

\section{b. The relative roles of tropical Pacific and tropical Atlantic forcing of interannual variability of precipitation over the American West}

For the 1979 to 2005 period the correlation coefficient between the GOGA precipitation and the observed precipitation is 0.57 for GPCP and 0.66 for the GHCN, indicating that just over a third of the precipitation variability is accounted for by SST forcing. For the POGA-ML model the correlations are 0.45 and 0.52 , so just under a quarter of the variability can be accounted for by tropical Pacific SST forcing alone. Consequently SSTs outside of the tropical Pacific do lead to a modestly more realistic model simulation of precipitation in the American West.

To examine this we correlated the observed annual mean SSTs with the observed precipitation time series and then did the same for the GOGA and POGA-ML models (Fig. 2). All the SST patterns show an El Niño signal with a warm tropical Pacific Ocean, but there are noticeable differences in the Atlantic Ocean. The allobservational regressions and the GOGA regressions have a cooler than normal Atlantic Ocean associated with wet in the West, while the POGA-ML produces a warm Atlantic, consistent with a response to the El Niño state.

\footnotetext{
${ }^{2}$ A similar figure for low-pass filtered modeled and observed precipitation over the last century and a half is shown in S05b.
}
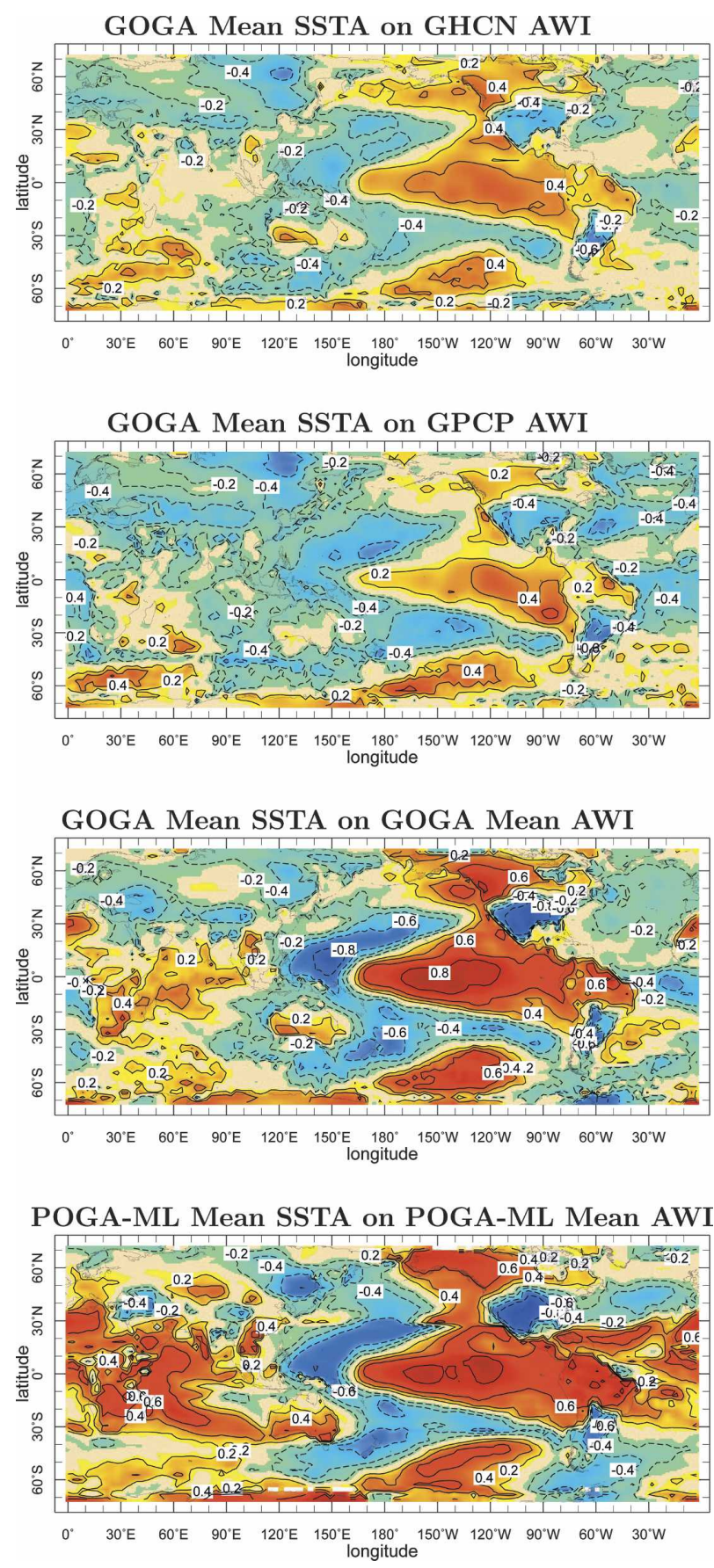

FIG. 2. The correlation coefficient between the annual mean precipitation averaged over the American West $\left(25^{\circ}-50^{\circ} \mathrm{N}, 125^{\circ}-\right.$ $90^{\circ} \mathrm{W}$ ) and global SST. (top) The correlation between the rain gauge GHCN data and observed SST; (second) the satellitederived GPCP precipitation; (third) the precipitation from the GOGA model and the global-observed SST used to force the GOGA model; and (bottom) the POGA-ML precipitation and the POGA-ML SST. For the model results the 16-member ensemble mean is shown. 
Annual GOGA - POGA-ML AWI (Dashed), TAl ${ }^{\star} 10$ (Solid) Corr -0.4499
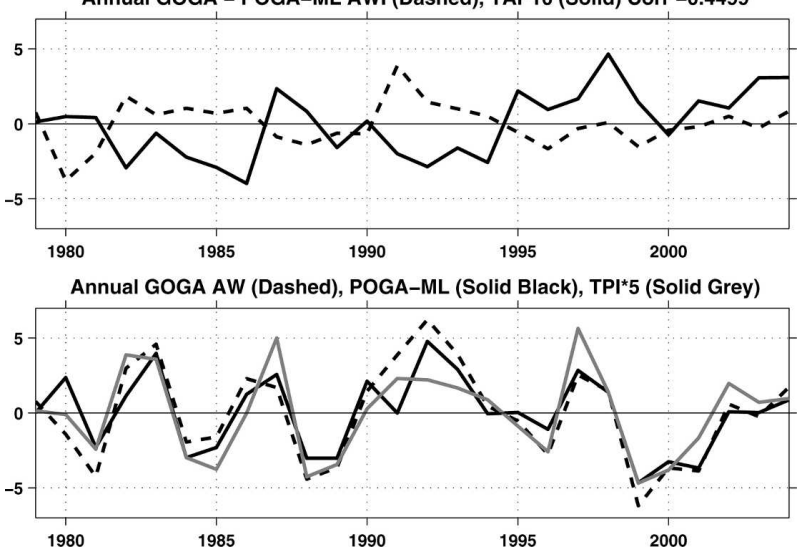

FIG. 3. (top) The annual mean difference in precipitation over the American West between the GOGA and POGA-ML models plotted together with the SST averaged over the tropical Atlantic Ocean from the equator to $25^{\circ} \mathrm{N}$. (bottom) The GOGA and POGA-ML precipitation over the West plotted with the tropical Pacific SST averaged over $5^{\circ} \mathrm{S}-5^{\circ} \mathrm{N}, 180^{\circ}-90^{\circ} \mathrm{W}$. The SST in $K$ has been multiplied by 10 in the top panel and 5 in the bottom panel for plotting and the precipitation is in $\mathrm{mm}$ month $^{-1}$.

Figure 3 shows that the time series of the precipitation in the West within the GOGA model minus that in the POGA-ML model is negatively correlated with an index of tropical Atlantic SST (average SST within the Atlantic between the equator and $25^{\circ} \mathrm{N}$ ). The lower panel of Fig. 3 shows the GOGA and POGA-ML simulations of precipitation in the West with an index of tropical Pacific SST (average SST over $5^{\circ} \mathrm{S}-5^{\circ} \mathrm{N}, 180^{\circ}-$ $90^{\circ} \mathrm{W}$ ). The primacy of tropical Pacific forcing is seen in that both models closely track the tropical Pacific SST history. However, the precipitation variations over the West are a little weaker in the POGA-ML model than in GOGA.

These results can be reconciled as follows. The observed and modeled precipitation over the West are strongly positively correlated with tropical Pacific SSTs and weakly negatively correlated with tropical Atlantic SSTs. In the real world, and the GOGA model, the tropical Atlantic SSTs include a component that is positively correlated to tropical Pacific SSTs [according to a well-established teleconnection mechanism (Alexander et al. 2002)] and other components related to Atlantic variability (e.g., Kushnir 1994; Seager et al. 2000) and climate "noise." In the POGA-ML model, by virtue of taking the ensemble mean, tropical Atlantic SST variability is tied to tropical Pacific SSTs. Hence, while El Niño increases the precipitation over the West, the El Niño-induced warming of the tropical Atlantic Ocean offsets this by a modest amount. This negative feedback is less active in the GOGA model and observations because those contain variations of tropical Atlantic SSTs unrelated to the tropical Pacific.

These results support suggestions that tropical Atlantic SST anomalies influence North American precipitation (Schubert et al. 2004b; Sutton and Hodson 2005; Enfield et al. 2001; McCabe et al. 2004) but make clear that this is a secondary influence relative to the tropical Pacific forcing. ${ }^{3}$ The 1979 to 2005 comparison suggests the models are sufficiently capable of capturing yearto-year variations of precipitation in the American West and that they are valid tools for examining the character and dynamics of the turn of the century drought.

\section{The global context of the turn of the century drought}

Almost all of North America endured a severe drought during the persistent La Niña of 1998-2002. Beginning in spring 2002 waters in the eastern equatorial Pacific warmed and remained warm until the end of 2005. Despite this change in tropical SSTs the drought over western North America persisted. Heavy rain and snow in the Southwest in winter 2004/05 ended the drought there while it persisted farther north. Because of this evolution, we examine two periods, one from fall 1998 to spring 2002 and one from spring 2002 until fall 2004, dividing each into summer (April through September) and winter (October through March) half years.

In Fig. 4 we show the difference in precipitation for the two seasons of the period from October 1998 to March 2002 relative to the entire period from January 1979 to April 2005 using GPCP satellite-gauge data and the ensemble mean of the models. Both the winters and summers of this period were dry throughout North America. As discussed by Hoerling and Kumar (2003), and as seen in Fig. 4, this drought was part of a pattern with noticeable zonal symmetry: drought also extended across the midlatitude North Atlantic Ocean, the Mediterranean, and into Central Asia (Barlow et al. 2002).

There was also a near-zonal band of reduced precipitation in the Southern Hemisphere midlatitudes during the October-March season. This is akin to the hemispherically symmetric patterns of precipitation variability on interannual (S05a) and decadal (Schubert et al. 2004a; Huang et al. 2005; S05b) time scales previously identified. The hemispheric symmetry is, however, less obvious than in those studies. In particular, it is normal

\footnotetext{
${ }^{3}$ The mechanisms whereby tropical Atlantic SSTs influence North American precipitation are yet to be explained.
} 


\section{Apr-Sep 1999-2001}

\section{Oct-Mar 1998-2002}

\section{GPCP Precipitation}
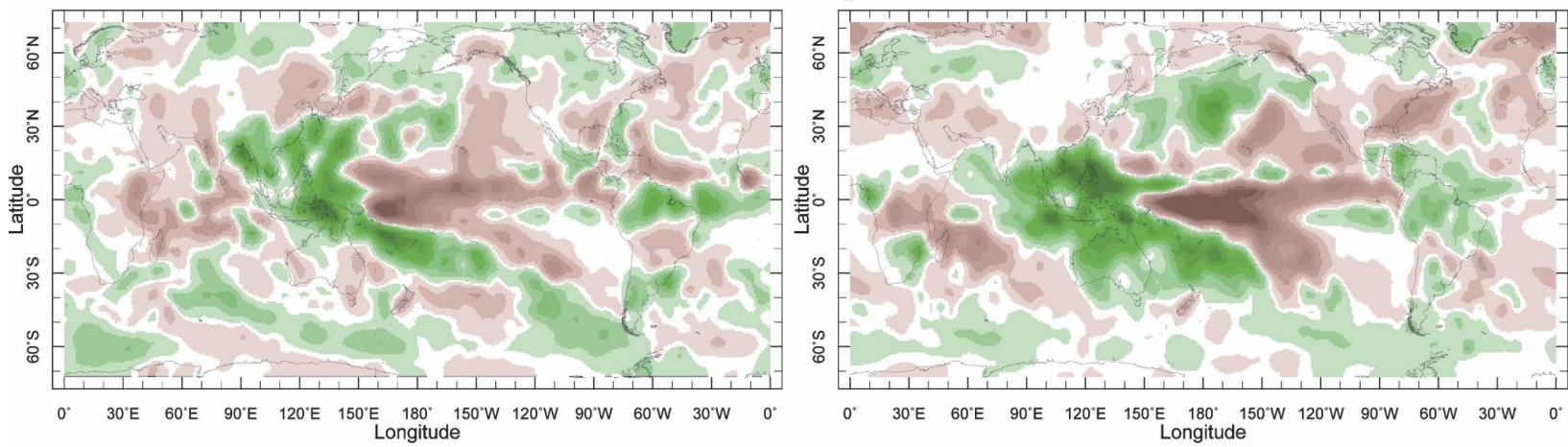

POGA-ML Precipitation
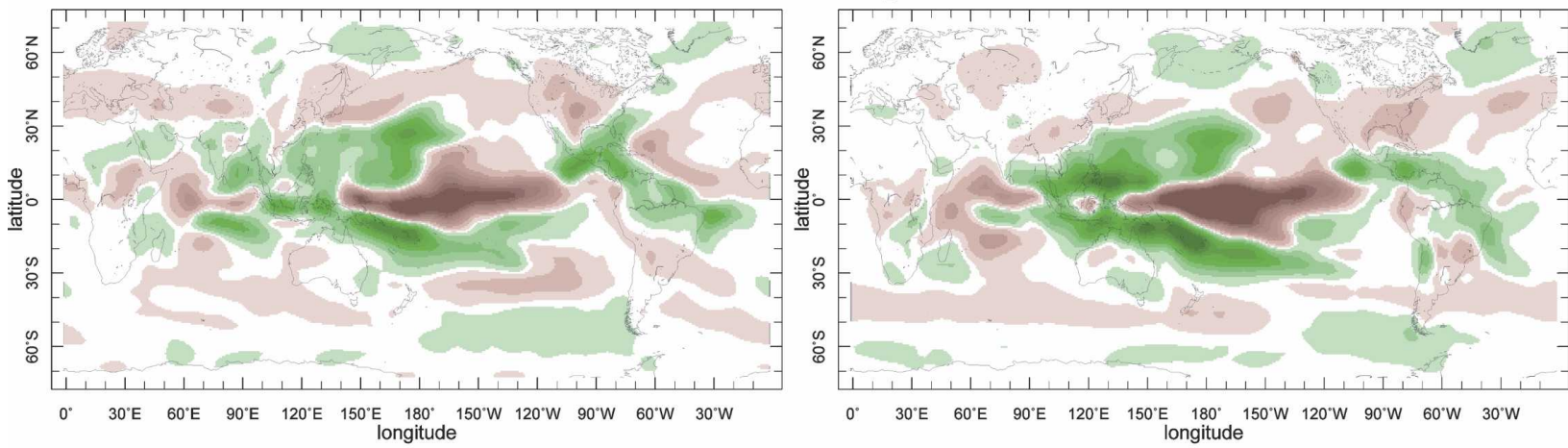

GOGA Precipitation

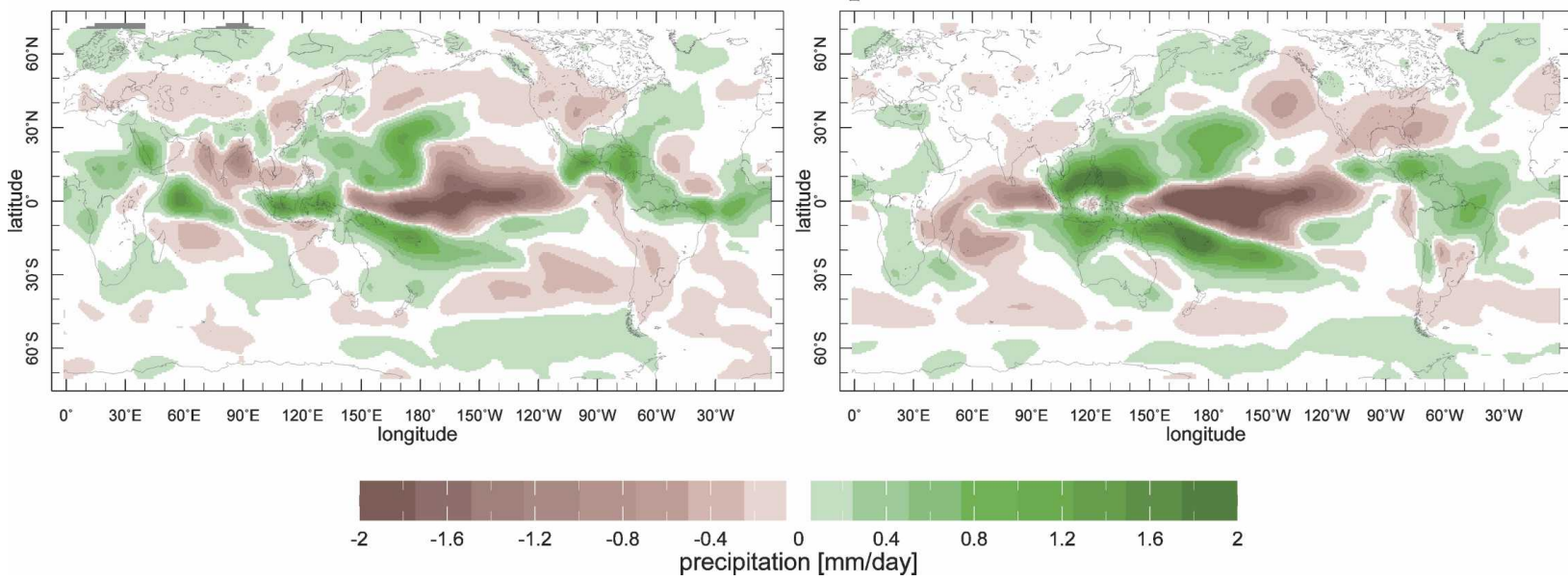

FIG. 4. The observed precipitation anomaly for the 1998-2002 period, relative to the 1979 through 2005 base period, shown for the northern (left) summer and (right) winter half years, together with that simulated by the (middle) POGA-ML and (bottom) GOGA models. Units are $\mathrm{mm} \mathrm{day}^{-1}$.

for southern South America-from southern Brazil to Cape Horn— to be dry during La Niñas, but during this period this region was wet, for unexplained reasons.

The observed SST anomalies during the 1998 to 2002 period, relative to the January 1979 through April 2005 base period, are shown in Fig. 5. La Niña-like conditions prevailed in the Pacific Ocean with cold along the equator in the eastern and central equatorial Pacific and along the west coast of the Americas and warm waters in the western equatorial, subtropical, and mid- 
Apr-Sep 1999-2001

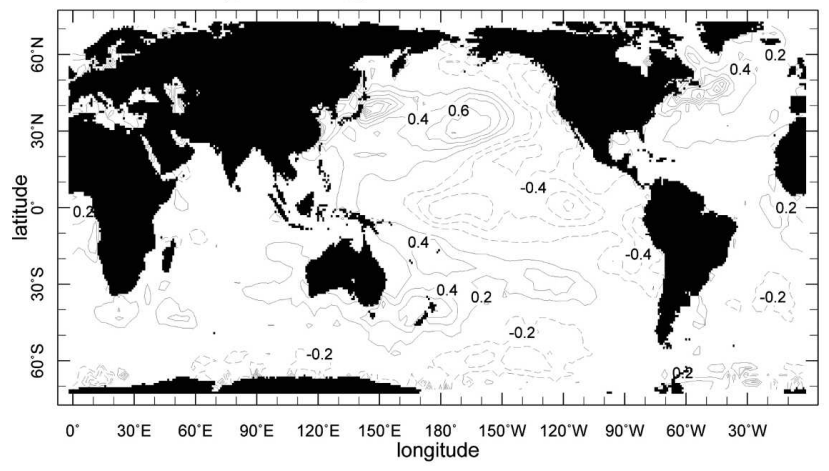

Apr-Sep 2002-2004

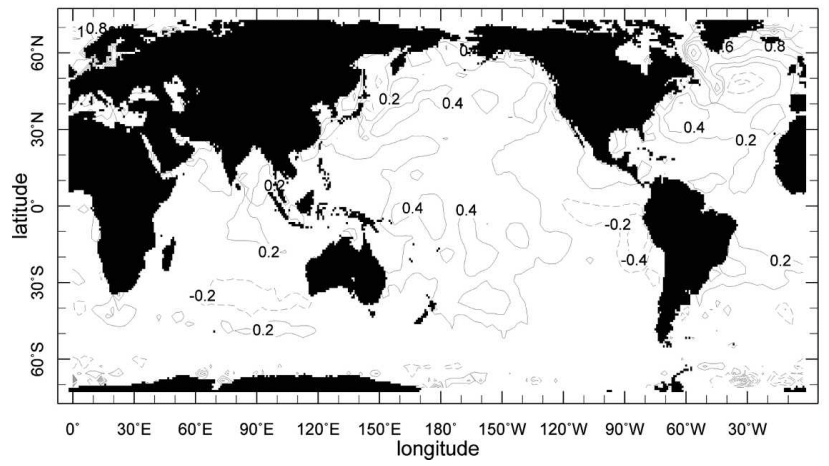

Oct-Mar 1998-2002

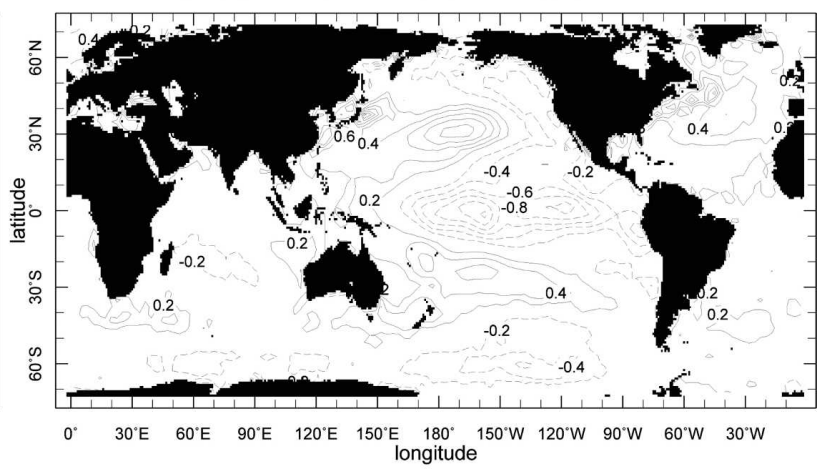

Oct-Mar 2002-2004

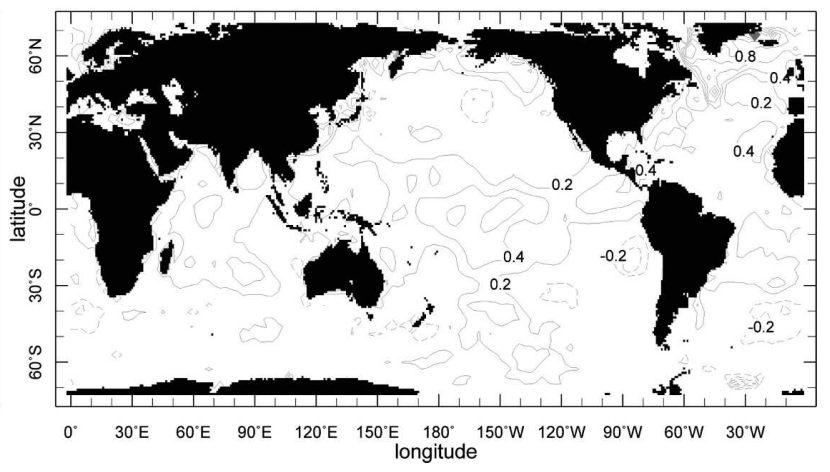

FIG. 5. The observed SST anomaly for (top) the 1998-2002 period and (bottom) the 2002-04 period relative to the 1979-2005 base period, shown for the northern (left) summer and (right) winter half years. Units are ${ }^{\circ} \mathrm{C}$.

latitude Pacific Ocean in both hemispheres. Relative to this post-1979 base period the Indian Ocean SST anomalies were small.

The middle and lower panels of Fig. 4 show the precipitation anomaly simulated by the POGA-ML and GOGA models. The tropically forced model (POGAML) has reduced precipitation across North America in both seasons as part of distinct bands of reduced precipitation in the midlatitudes of each hemisphere. The precipitation patterns in the Tropics are also similar to those observed: reduced precipitation along the equatorial Pacific Ocean; increased precipitation over Southeast Asia, the Maritime Continent, and tropical South America; and dry conditions over parts of central Africa. The GOGA precipitation is generally very similar, emphasizing the importance of tropical Pacific SSTs. The most obvious failings are in the southern midlatitudes where the model precipitation is far more zonal than observed.

Figures 5 and 6 show the corresponding SST and precipitation patterns for the later, 2002-04, period. The protracted La Niña is now gone. Precipitation increases in the tropical Pacific intertropical convergence zone. The dryness in southern Europe and central Asia ended in this period but persisted over North America. Both the POGA-ML and GOGA model ensemble means reproduce many of these changes going over in October-March 2002-04 to a typical El Niño-like pattern of precipitation anomalies. As such they make North America wet and fail to reproduce the continuation of the drought. Clearly 2002 brought a change in the global hydroclimate, and the most recent part of the turn of the century drought in the West is dynamically distinct from the four prior years.

Focusing now on the earlier period of the drought, which the model simulations suggest was SST forced, the observed 200-mb geopotential height anomalies, relative to the 1979 to 2005 period, are shown in Fig. 7. In the observations, above the equatorial Pacific Ocean during the boreal winters of the drought, a La Niña signal is seen with low heights extending throughout the Tropics. There are zonally elongated ridges in the subtropics of each hemisphere, as noted by Lau et al. (2006), with low heights farther poleward.

Both the POGA-ML and GOGA models capture the tropical lows and midlatitude zonal ridges in each hemi- 


\section{Apr-Sep 2002-2004}

\section{Oct-Mar 2002-2004}

\section{GPCP Precipitation}
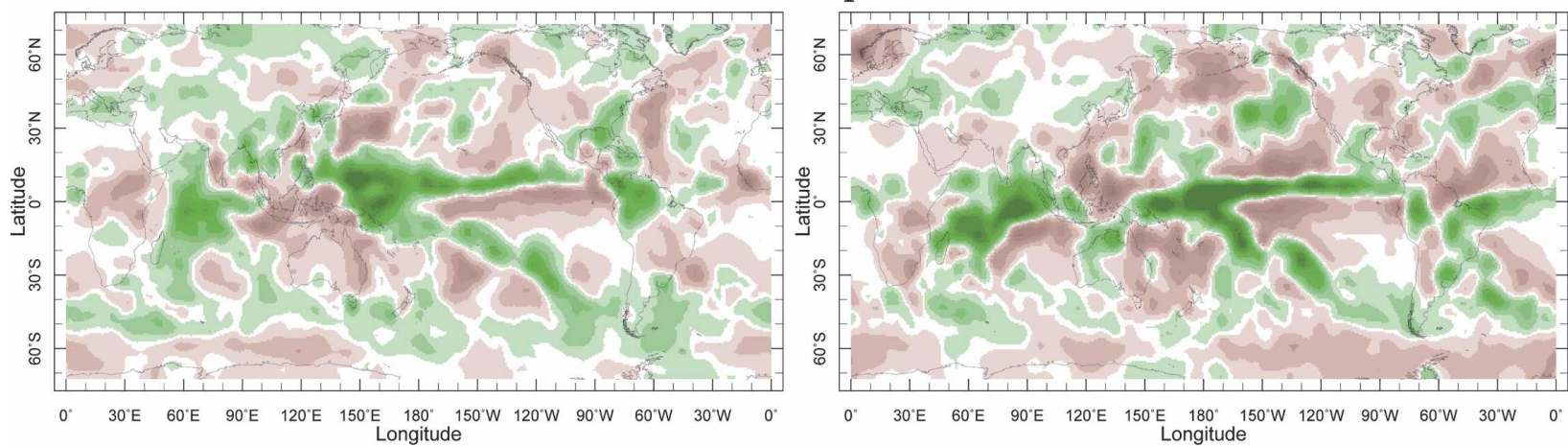

POGA-ML Precipitation
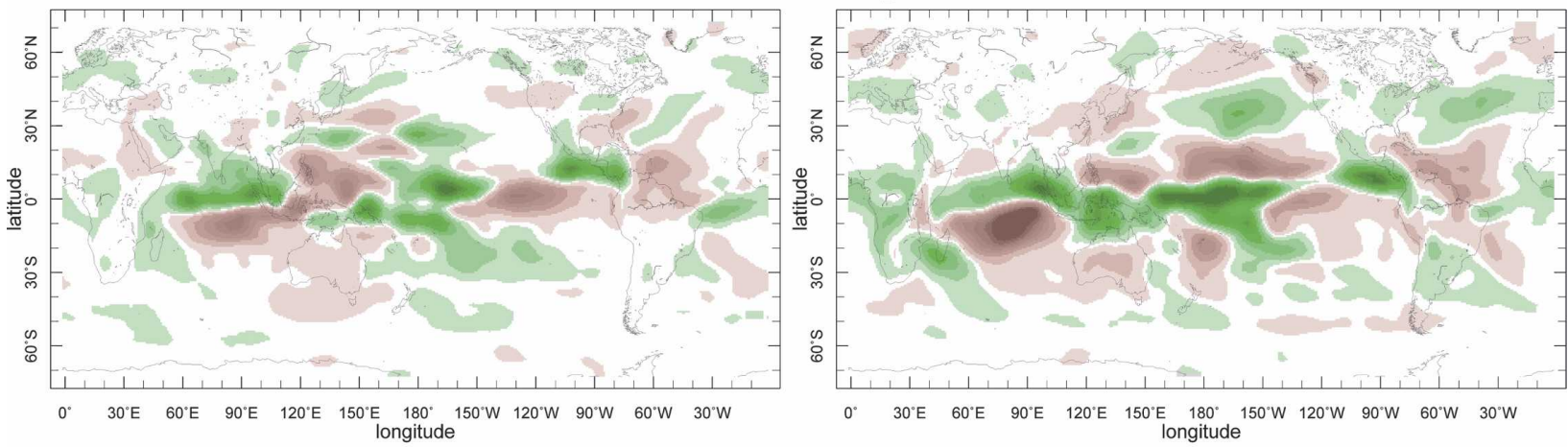

GOGA Precipitation
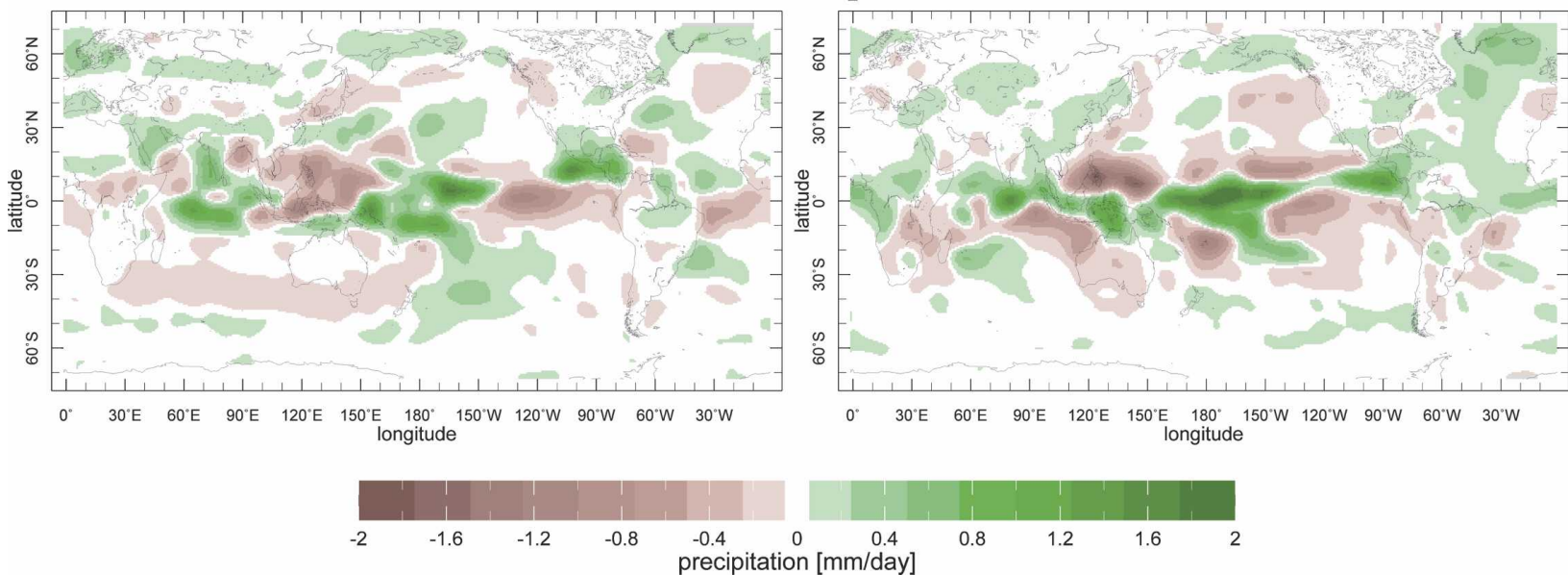

FIG. 6. As in Fig. 4, but for the period from April 2002 to September 2004,

sphere and each season (Fig. 7). In the region of the North Pacific and North America the height anomalies are typical of those occurring during cold events in the tropical Pacific Ocean (see Fig. 12 of Hoerling and Kumar 2002). The models fail to reproduce the increases in height during local winter in the polar latitudes of both hemispheres. These errors could be related to aspects of annular mode dynamics that the model does not capture and, perhaps, cannot be expected to, given that it was only forced by variations of SSTs.

By the later part of the North American drought period the observed tropical heights had become posi- 


\section{Apr-Sep 1999-2001}

\section{Oct-Mar 1998-2002}

\section{NCEP}
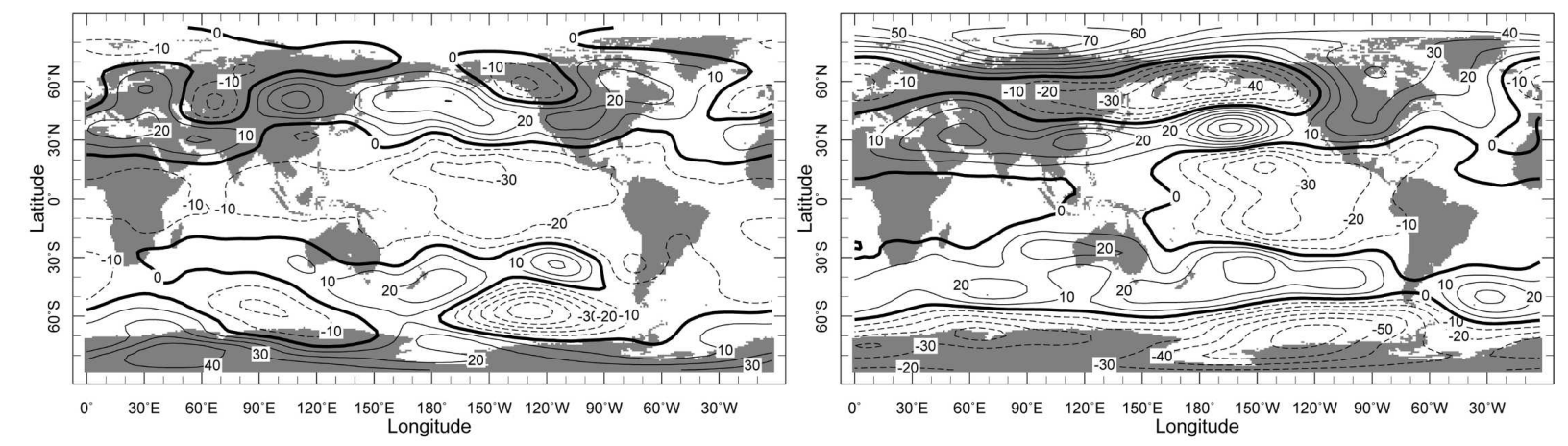

\section{POGA-ML}
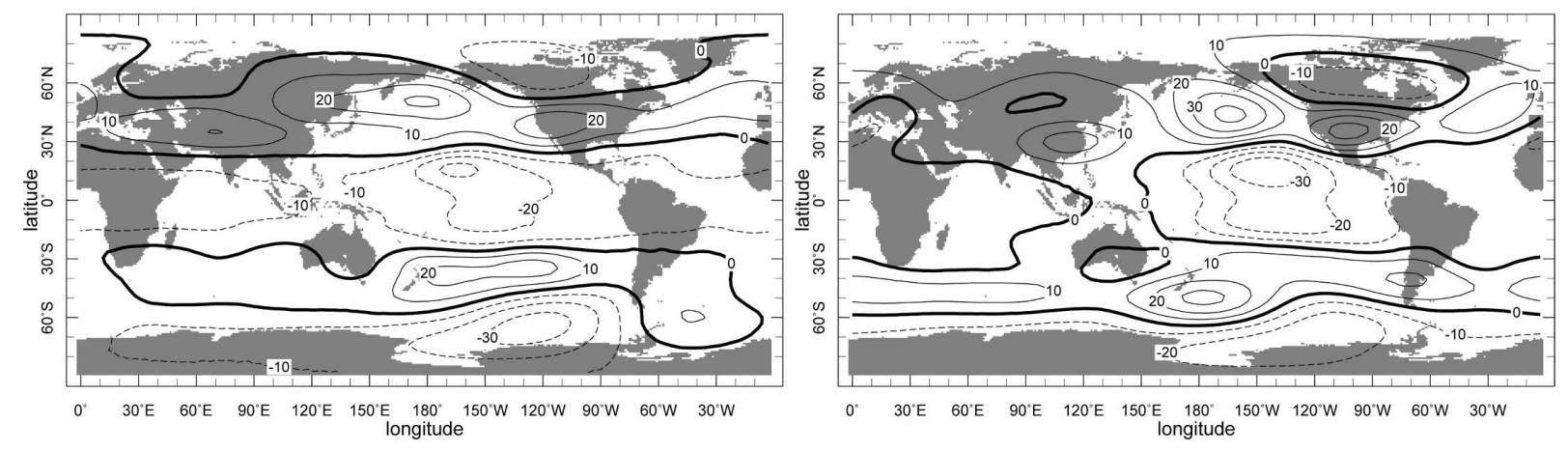

200. mb

200. $\mathrm{mb}$

\section{GOGA}
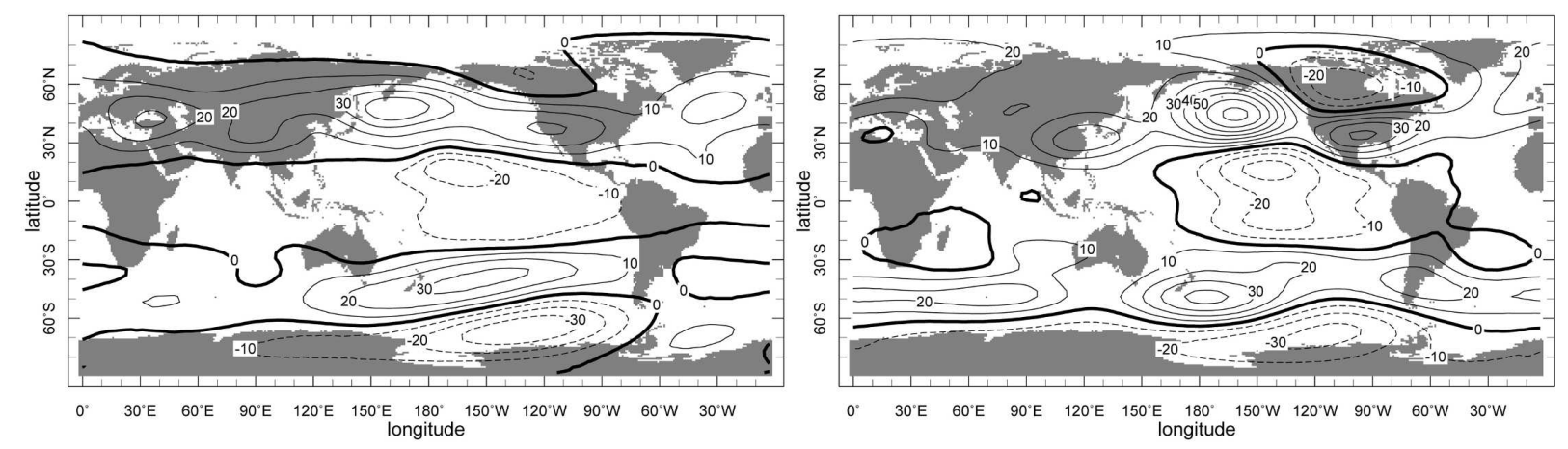

200. mb

200. $\mathrm{mb}$

FIG. 7. (top) The observed 200-mb geopotential height anomaly for the 1998-2002 period relative to the 1979 through 2005 base period, shown for the (left) summer and (right) winter seasons, together with that simulated by the (middle) POGA-ML model and (lower) GOGA model. Units are m.

tive (Fig. 8), consistent with tropical Pacific Ocean warming, and the subtropical ridges disappear. During winter 2002-04 midlatitude heights were generally low, typical of an El Niño winter. This shift to a more El Niño-like state is quite well reproduced by the POGAML model (middle panels of Fig. 8).

\section{A zonal mean perspective on the turn of the century North American drought}

Next we turn to an analysis of the zonal mean hydroclimate of the 1998 to 2004 period. Figure 9 shows the zonal mean anomalies in observed and modeled pre- 


\section{Apr-Sep 2002-2004}

\section{Oct-Mar 2002-2004}

\section{NCEP}
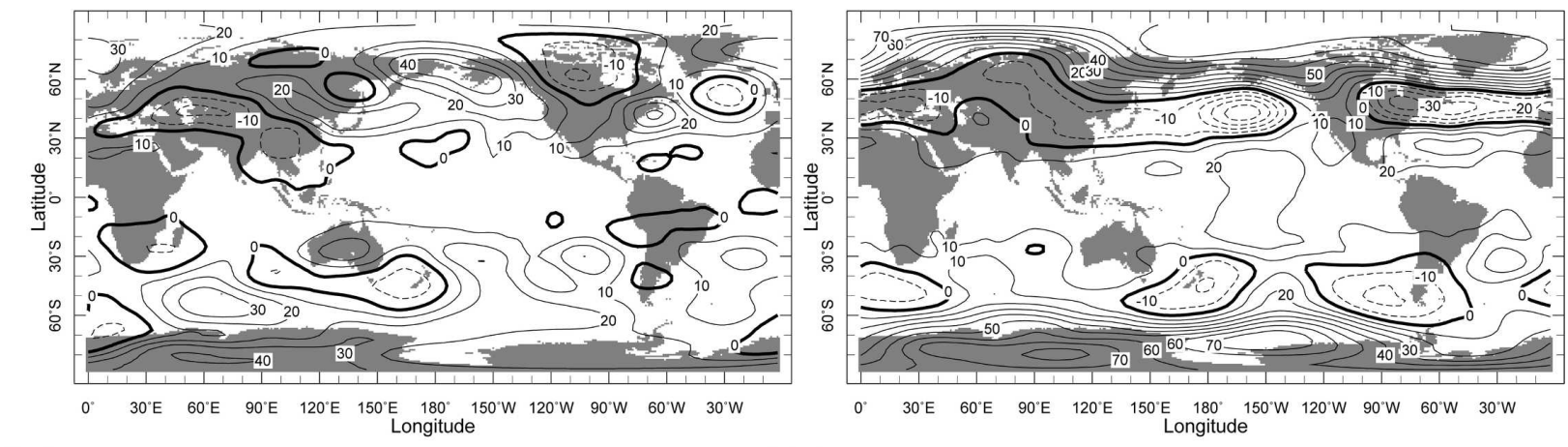

\section{POGA-ML}
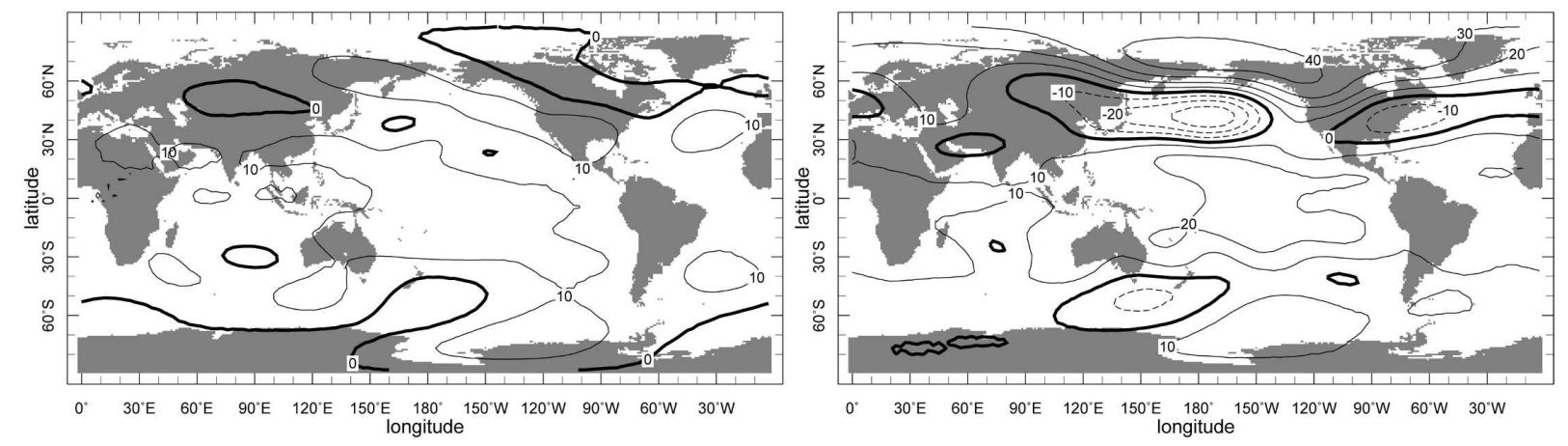

200. $\mathrm{mb}$

200. $\mathrm{mb}$

\section{GOGA}
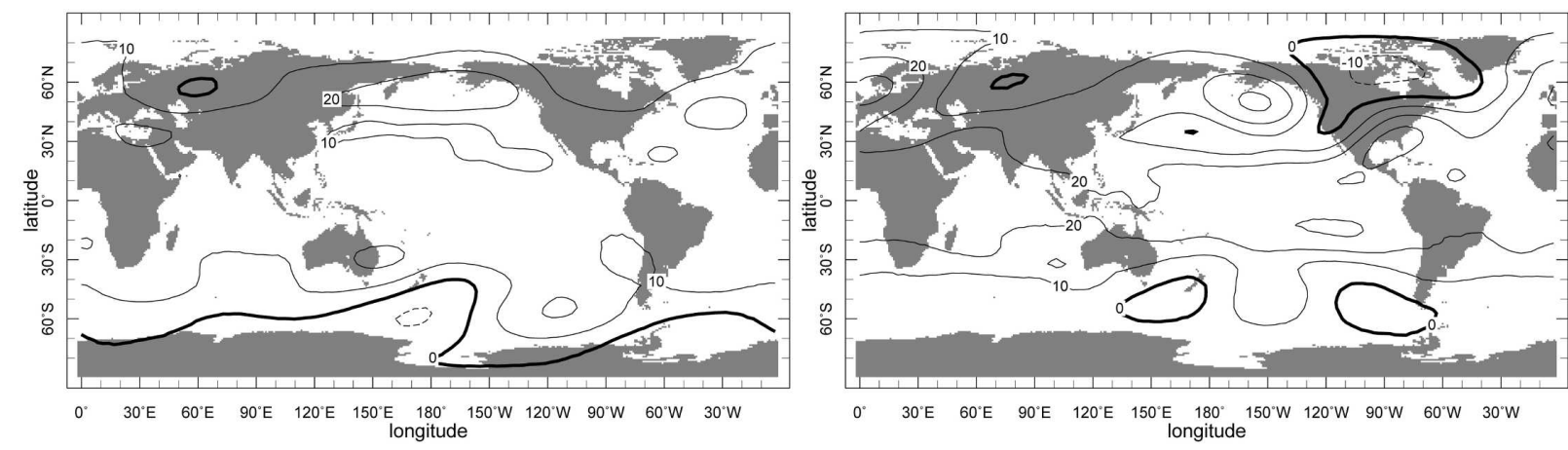

200. $\mathrm{mb}$

200. $\mathrm{mb}$

FIG. 8. As in Fig. 7, but for April 2002-September 2004.

cipitation for the period of protracted La Niña and North American drought (fall 1998 to spring 2002). In nature, during both half years, there is a reduction of precipitation at the equator, increases in the subtropics, and decreases in the midlatitudes of each hemisphere, a pattern akin to that associated with interannual ENSO variability (S05a). The GOGA and POGA-ML models qualitatively capture these changes and quantitatively capture the reduction of summer precipitation in the northern midlatitudes. ${ }^{4}$ The models fail to simulate the lack of drought in the southern midlatitudes in both

\footnotetext{
${ }^{4}$ The overestimation of the equatorial reduction of precipitation arises because the model has ENSO-related precipitation anomalies of the same sign across the Pacific in contrast to the more zonally varying pattern in nature (see S05a).
} 


\section{Apr-Sep 1999-2001}

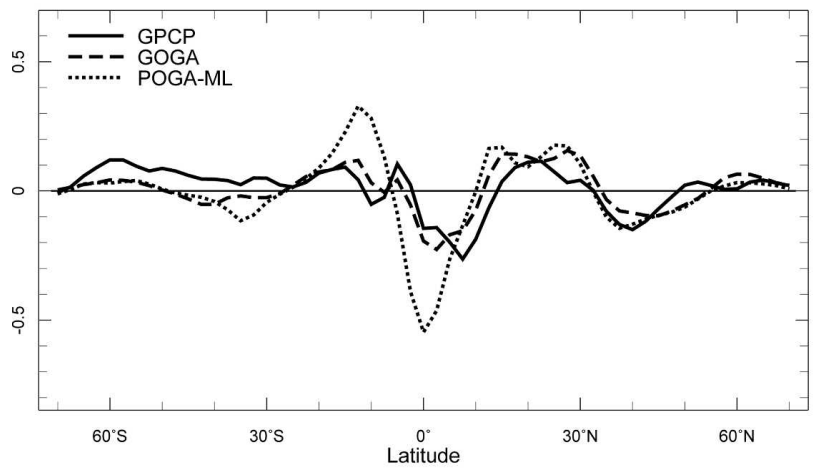

Apr-Sep 2002-2004

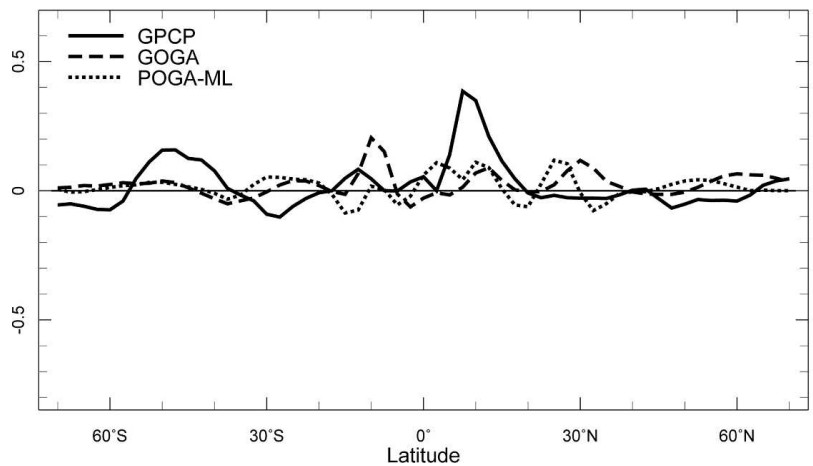

Oct-Mar 1998-2002

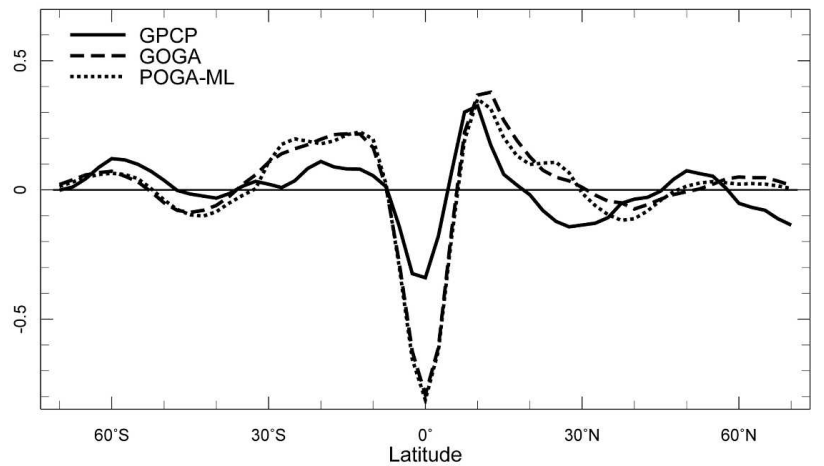

Oct-Mar 2002-2004

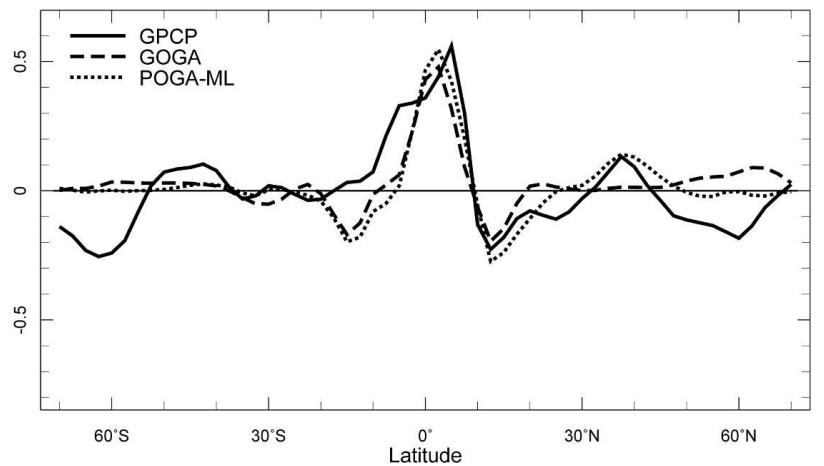

FIG. 9. The observed and modeled zonal mean precipitation anomalies for northern (left) summer and (right) winter half years of the (top) 1998-2002 period and (bottom) 2002-04 period relative to the 1979 to 2005 base period. Observations are from GPCP (solid) and both the GOGA (dashed) and POGA-ML (dotted) model simulations are shown. Units are mm per day.

seasons. The GOGA model does not out perform the POGA-ML model in any significant way.

The lower panels show the observed and modeled precipitation for the 2002-04 period. During northern winters the tropical signal has now reversed, consistent with the change in SST. The northern summer signal is incoherent. During the northern winters there is reduced precipitation in the northern subtropics, more precipitation between $30^{\circ}$ and $40^{\circ} \mathrm{N}$, and less north of there, typical of El Niño conditions (S05a). The models reproduce this in the Tropics and northern subtropics and midlatitudes but miss the generally reduced precipitation north of $40^{\circ} \mathrm{N}$. The POGA-ML model simulates the increase in northern midlatitude precipitation in the winter half year, but the GOGA model does not.

Figure 10 shows the observed and simulated changes in zonal mean temperature and zonal wind for the two seasons of the 1998 to 2002 period. Both model and observations show the clear sign of a protracted La Niña, akin to the interannual case (S03): the tropical troposphere is cooler than normal with maximum cool- ing in the upper troposphere, the subtropical jets in each hemisphere are weaker, and the midlatitude troposphere warms, accompanied by stronger westerlies on its poleward flanks. As shown in S05a, the change in the subtropical jet strength, which is hemispherically symmetric, arises as an eddy-mediated consequence of the tropical tropospheric temperature change and is not due to a change in the Hadley cell strength.

S03 show that the changes in the subtropical jets cause a change in the eddy momentum transport of transient eddies as their propagation responds to the change in mean flow. This is seen in Fig. 11, which shows the observed and modeled changes in the zonalmean meridional flux of zonal momentum by transient eddies $\left(\overline{u^{\prime} v^{\prime}}\right)$. There are regions of equatorward momentum flux in the subtropical free troposphere flanked by poleward flux anomalies farther poleward [typical of interannual (S03) and protracted (S05b) La Niña events]. The transient-eddy momentum flux convergence is primarily balanced by the Coriolis torque associated with the mean meridional velocity. 


\section{Apr-Sep 1999-2001}

\section{Oct-Mar 1998-2002}

\section{NCEP}
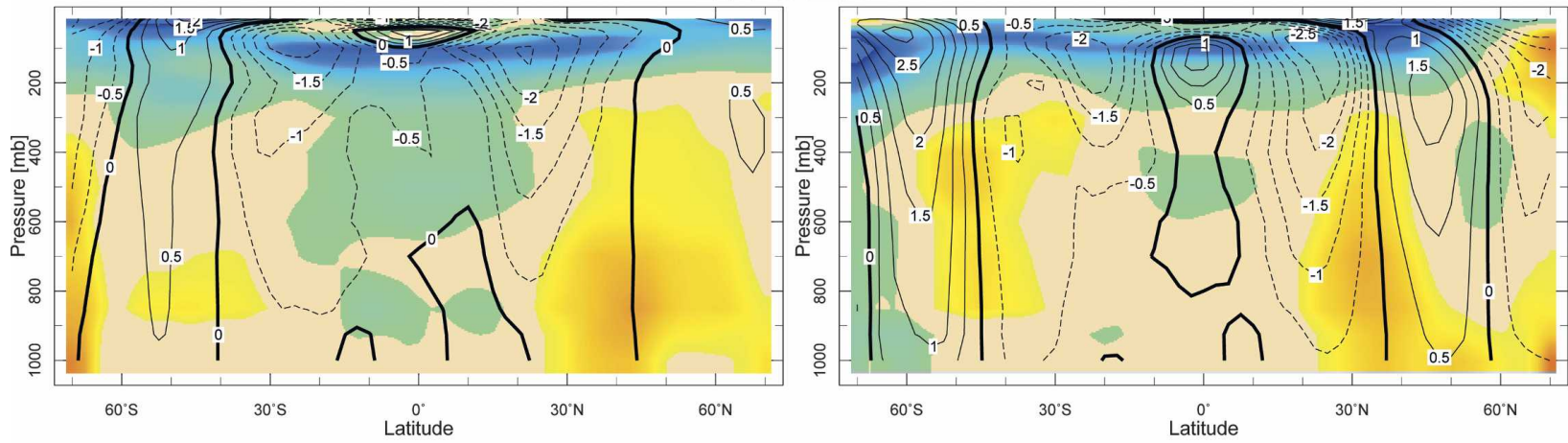

POGA-ML
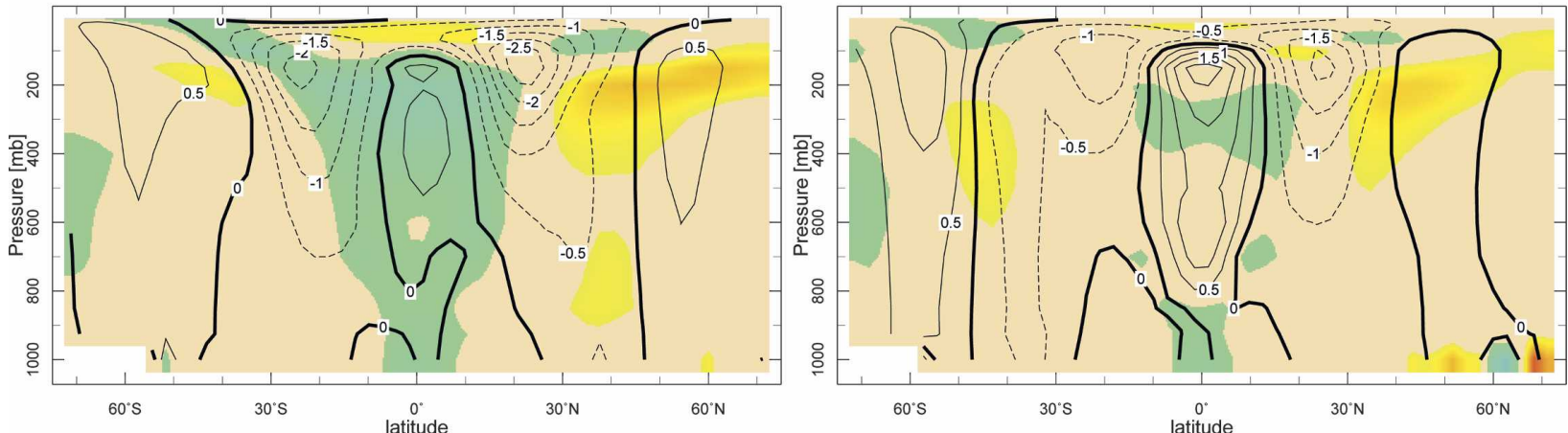

GOGA
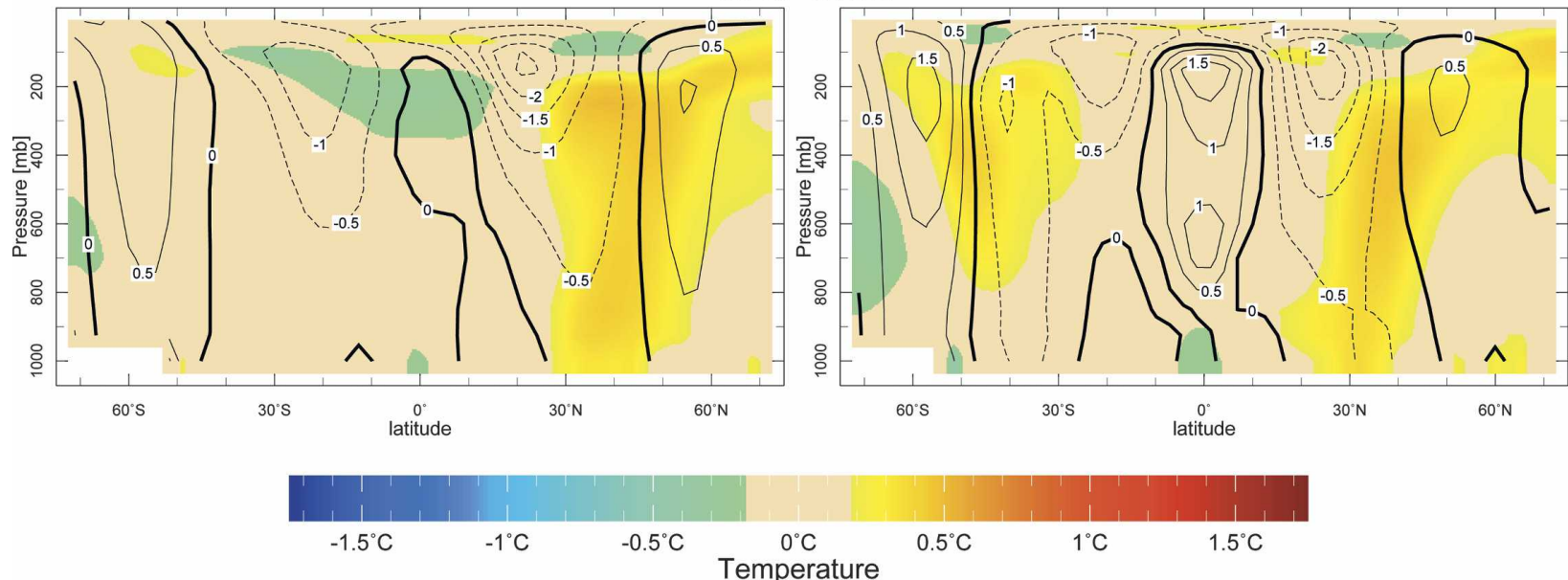

FIG. 10. The observed and modeled zonal mean temperature (colors) and zonal wind (contours) anomalies for northern (left) summer and (right) winter half years of the 1998-2002 period relative to the 1979 to 2003 base period. Observations are from the NCEP-NCAR reanalysis and both the POGA-ML and GOGA models are shown. Units are ${ }^{\circ} \mathrm{C}$ and $\mathrm{m} \mathrm{s}^{-1}$.

Thus there will be poleward flow in the subtropical upper troposphere that will induce descent in midlatitudes.

The anomalies in zonal mean subsidence are also shown in Fig. 11. The models show a clear relationship between subsidence and momentum fluxes along the lines expected and in both seasons and hemispheres. The observed quantities are more noisy but suggest a similar relationship. Disagreement indicates contributions to the subsidence from other terms, and we will 


\section{Apr-Sep 1999-2001}

NCEP

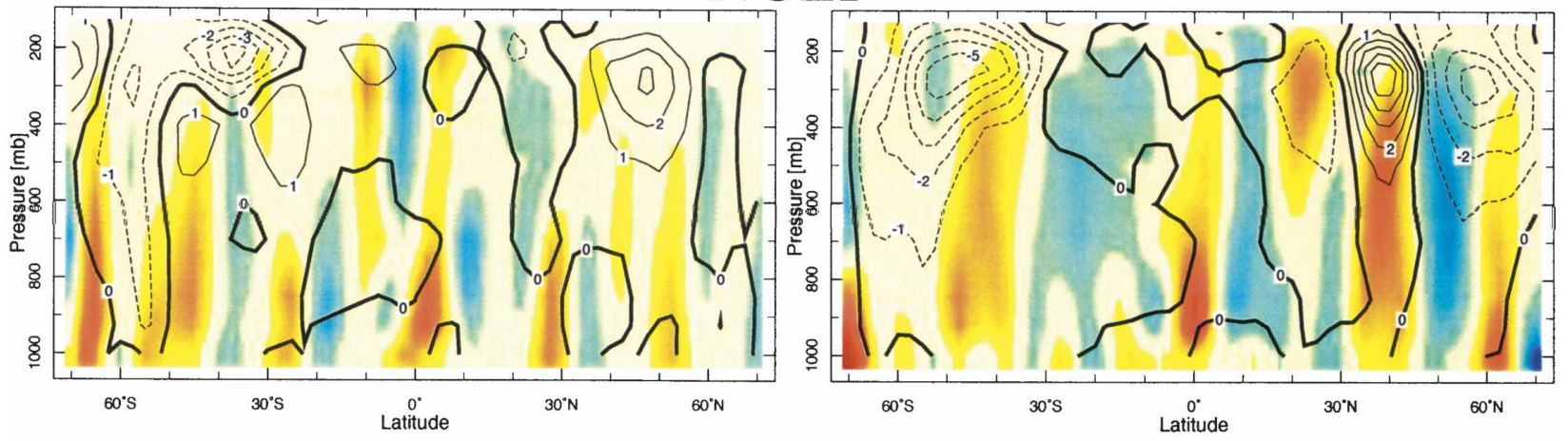

POGA-ML

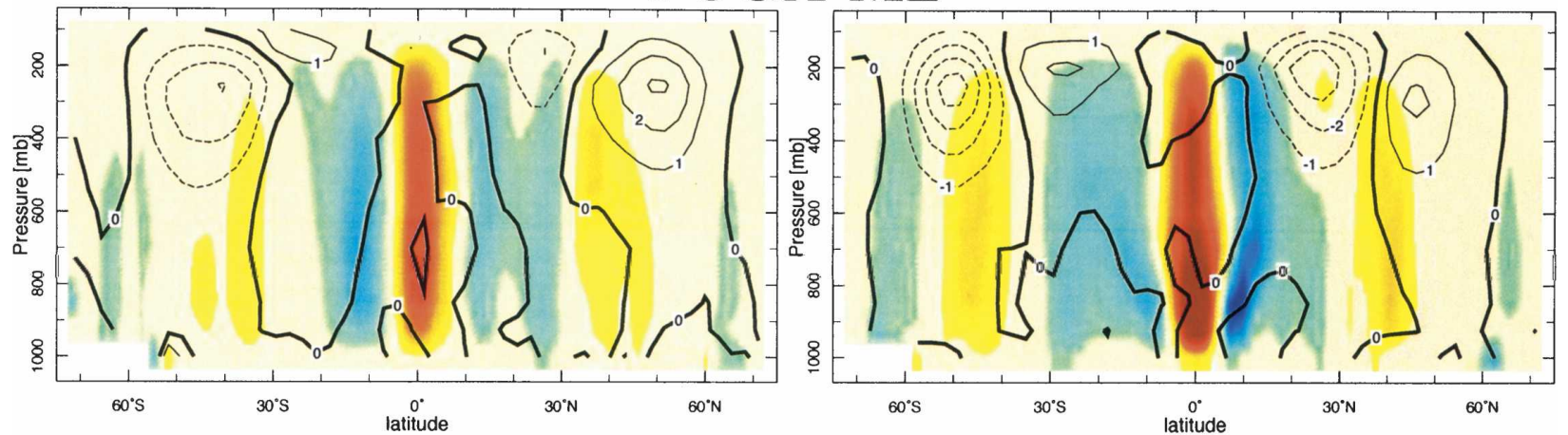

GOGA

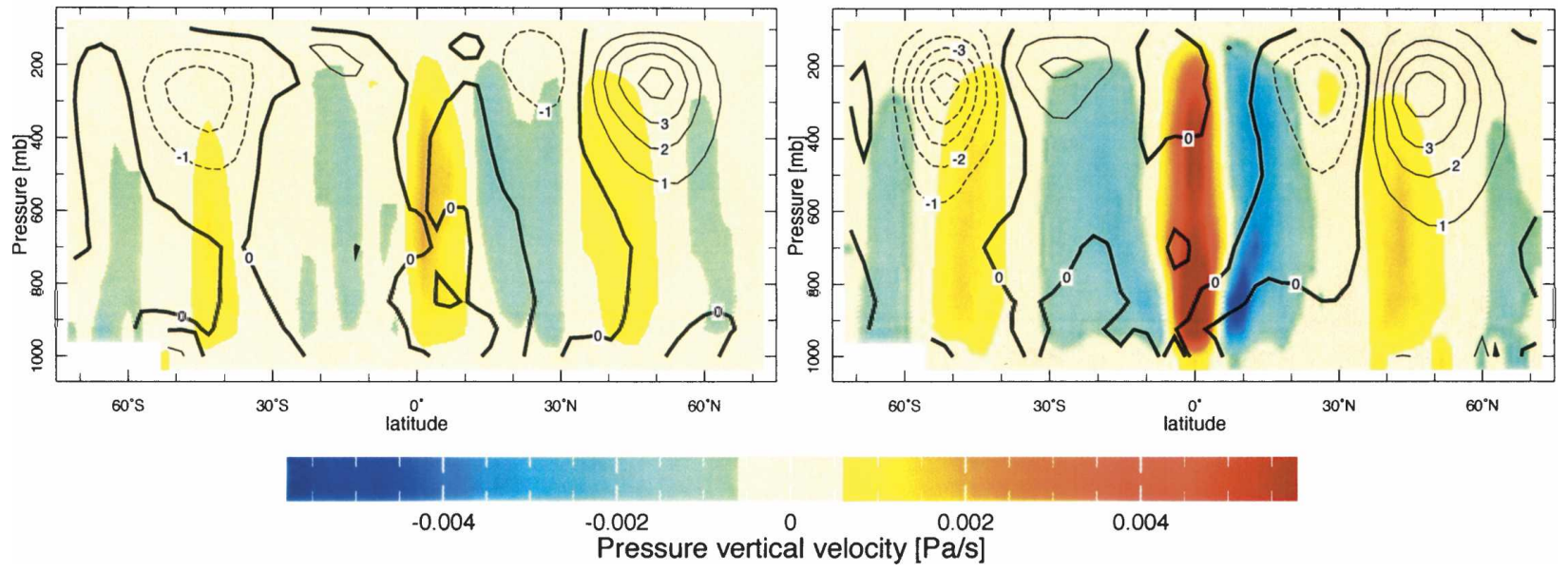

FIG. 11. The observed and modeled anomalies of zonal mean subsidence ( $\omega$, colors) and meridional transport of zonal momentum by transient eddies $\left(\overline{u^{\prime} v^{\prime}}\right.$, contours) for northern (left) summer and (right) winter half years of the 1998-2002 period, relative to the 1979-2003 base period. Observations are from the NCEP-NCAR reanalysis and both the POGA-ML and GOGA model simulations are shown. Units are $\mathrm{Pa} \mathrm{s}^{-1}$ and $\mathrm{m}^{2} \mathrm{~s}^{-1}$.

show that the stationary eddy momentum fluxes play a supporting role.

It is interesting to see how well the zonal mean change in modeled precipitation minus evaporation, $\langle\bar{P}\rangle-\langle\bar{E}\rangle$, where angle brackets indicate zonal means and overbars monthly means, can be explained solely by anomalies in the eddy-induced mean meridional circulation. To do this we imagine that the meridional mass flux above the boundary layer (taken to be the area below $850 \mathrm{mb}$ ) is driven by the transient and stationary eddy momentum fluxes in the free troposphere and that there is a compensating mass flow in the op- 


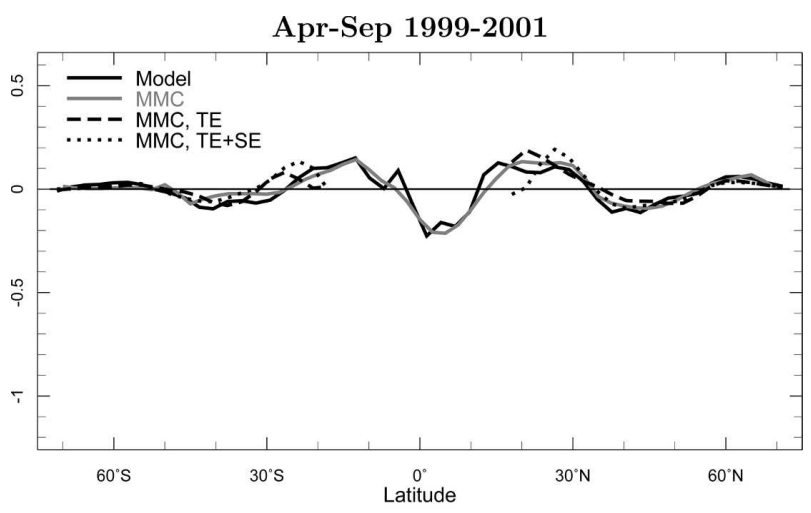

Oct-Mar 1998-2002

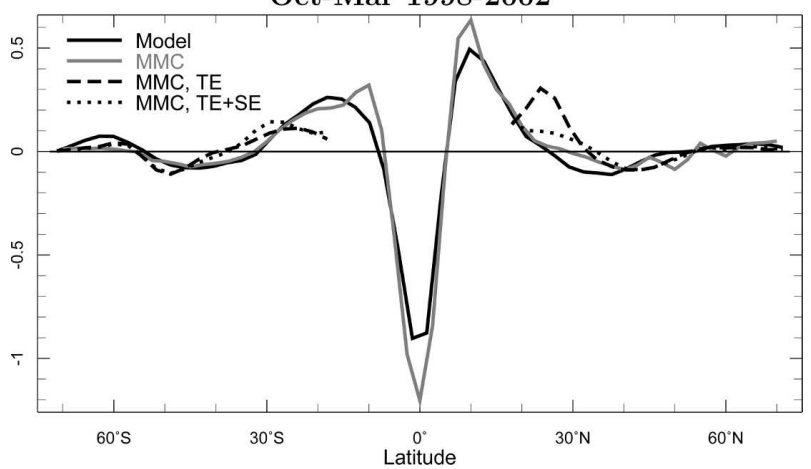

FIG. 12. The zonal mean anomaly in precipitation minus evaporation within the GOGA model (solid black), together with the contribution from the anomalous moisture transport by the mean meridional circulation (MMC, gray), the contribution from the anomalous transient eddy-driven MMC transporting the climatological moisture field (dashed), and the contribution from the transient plus stationary eddy-driven MMC transporting the climatological moisture field (dotted). Results are shown for the northern summer and winter half years of the 1998-2002 period. Units are $m m$ day $^{-1}$.

posite direction within the boundary layer. We then assume that this anomalous eddy-driven flow advects the climatological humidity field to create anomalies in $\langle\bar{P}\rangle-\langle\bar{E}\rangle$. Details of the calculation are in the appendix.

The modeled anomalies of $\langle\bar{P}\rangle-\langle\bar{E}\rangle$, the contribution from the complete MMC (computed using the actual model flow and allowing for changes in modeled humidity), the contribution attributable to a change in the transient eddy-induced MMC only, and the contribution attributable to changes in both the transient and stationary eddy-induced MMC are all shown in Fig. $12 .{ }^{5}$

\footnotetext{
${ }^{5}$ The eddy-induced $\langle\bar{P}\rangle-\langle\bar{E}\rangle$ is only shown away from the equatorial region because, where $f$ is small, errors in the computation of the right-hand side of Eq. (A2) (due to neglect of dissipation in the free troposphere and adoption of different computational methods than used in the actual GCM) lead to large errors in the meridional velocity and, hence, the moisture budget.
}

From Fig. 12 it is clear that at all latitudes anomalies of $\langle\bar{P}\rangle-\langle\bar{E}\rangle$ can be easily accounted for by a change in the moisture transport by the MMC. Further (not shown), the moisture transport by the MMC can be almost entirely accounted for by the change in the MMC and is not significantly impacted by anomalies in specific humidity. Away from the equatorial region, much of the change in the MMC can be explained as a change in the transient eddy-induced flow with the stationary eddy-induced component also being important in northern midlatitudes during summer. At least for the zonal mean, the moisture budget away from the equator can be conveniently simplified, to first order, with transient eddy momentum fluxes driving an anomalous MMC and acting as the mediator between tropical SSTs and extratropical hydroclimate.

Figure 13 shows the zonal mean temperature and wind anomalies for the 2002 to 2004 period. The summer signal is largely incoherent in both model and observations, but during the winter seasons the appearance of the weak El Niño of winter 2002/03 is evident. The model faithfully reproduces the observed tropical tropospheric warming and the strengthening of the subtropical jets.

In summary, the turn of the century North American drought fitted into a zonal-mean dynamical rearrangement typical of interannual and protracted La Niña events with characteristic changes in zonal mean temperatures, winds, eddy momentum fluxes, and the MMC. The anomalous, eddy-driven, MMC largely explains the changes in $\langle\bar{P}\rangle-\langle\bar{E}\rangle$. The zonal mean dynamical setup reversed in 2002 as the persistent $\mathrm{La}$ Niña ended, a change that was simulated by the models. This emphasizes that the last two years of the turn of the century North American drought (2003 and 2004) are dynamically distinct from the earlier years and were divorced from the usual global dynamical configuration.

\section{The dynamics of the turn of the century North American drought}

In this section we attempt to understand the changes in atmospheric circulation, moisture transports, and evaporation that made up the turn of the century North American drought.

\section{a. The moisture budget and maintenance of the modeled drought}

Figure 14 shows the observed GPCP precipitation over the North American region during the winter and summer half years of the 1998 to 2002 period together 


\section{Apr-Sep 2002-2004}

NCEP

\section{Oct-Mar 2002-2004}
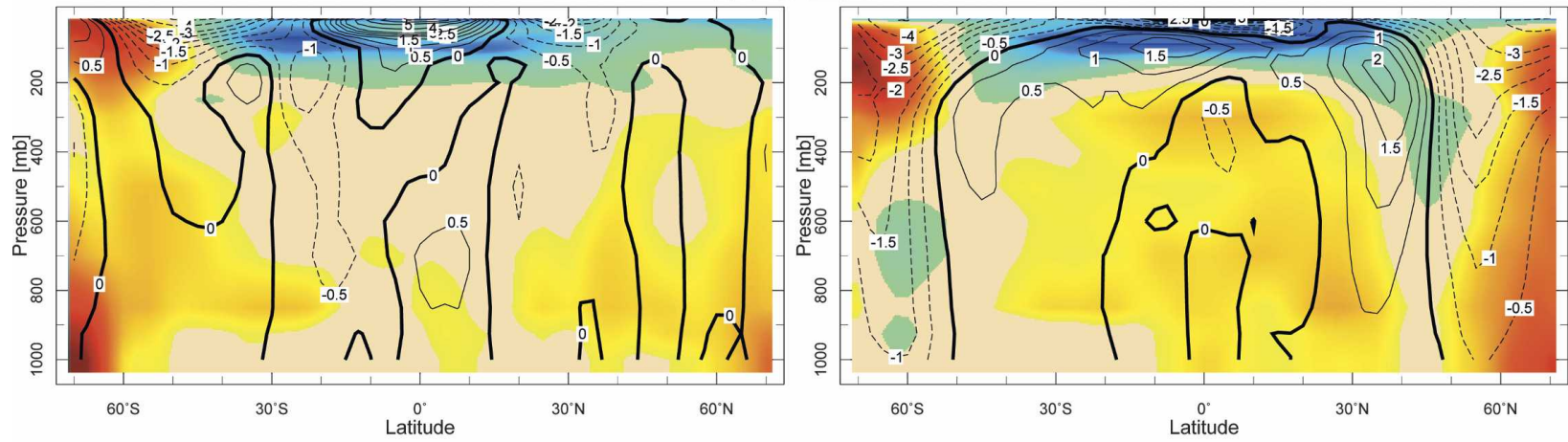

POGA-ML
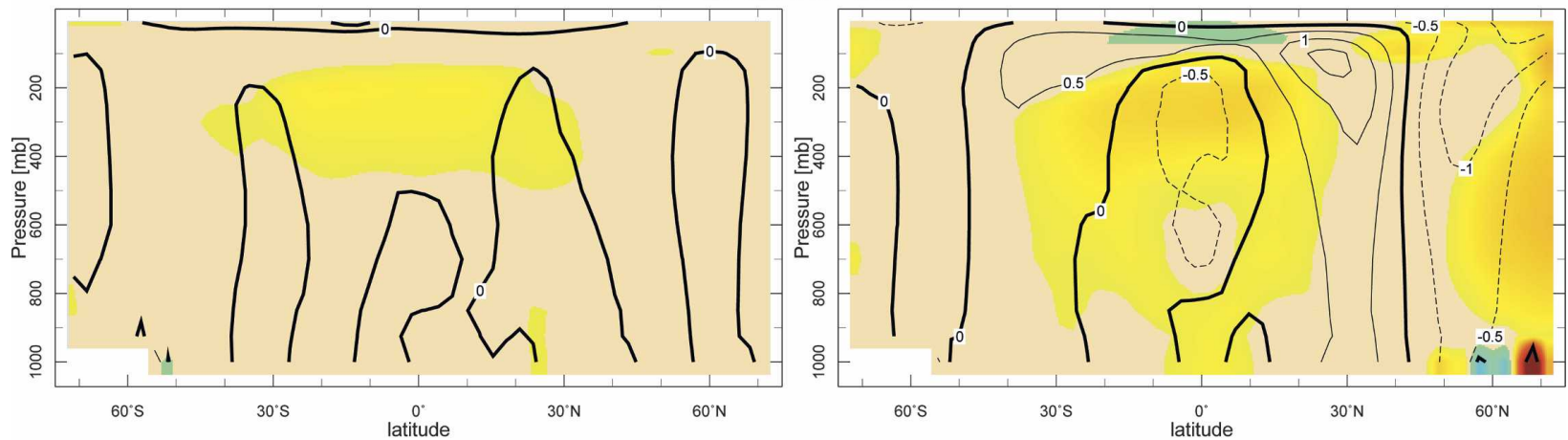

GOGA
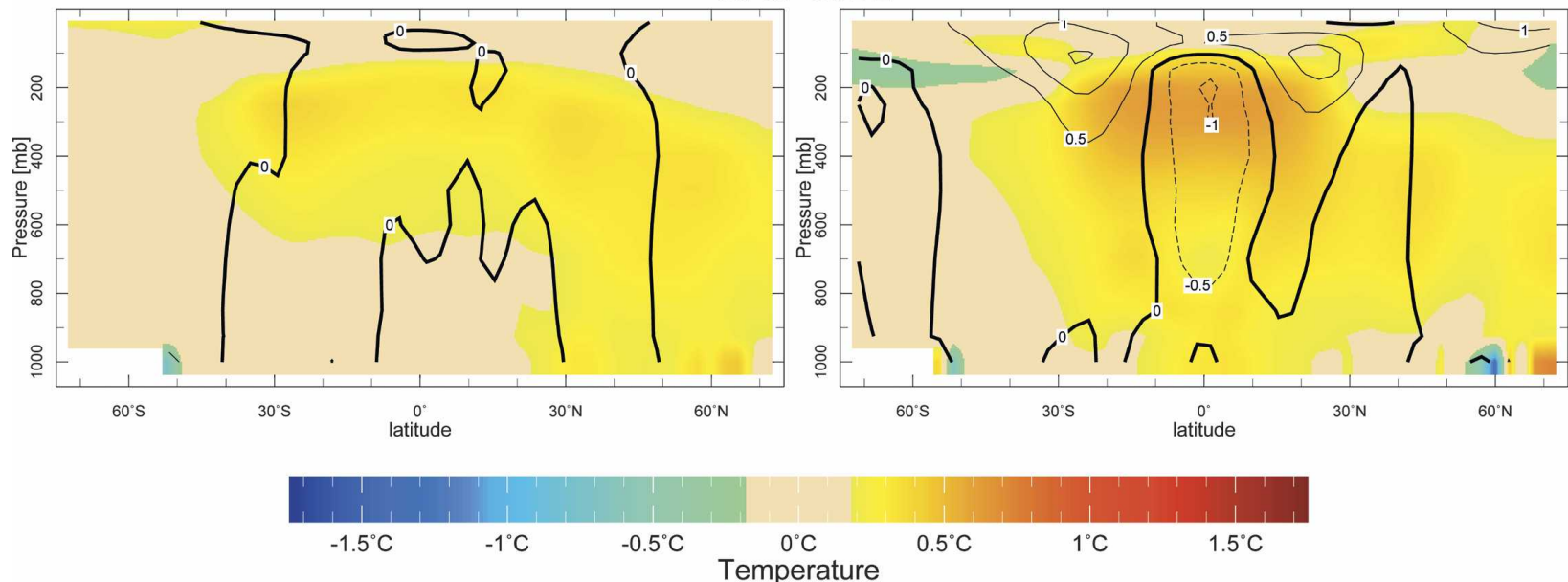

FIG. 13. As in Fig. 10, but for 2002-04.

with that from the GOGA and POGA-ML models. During the winter there was reduced precipitation across most of North America with the exception of British Columbia and northeastern Canada. The maximum reduction was in the southeastern United States. The modeled patterns are realistic but too weak. During the summer half years the observed precipitation reduction impacted the southern United States (except most of Florida) and the West. The model precipitation patterns are qualitatively realistic in that the South and West are dry while, correctly, Florida and southern Mexico are now wet. The models fail to simulate the wet conditions over central Canada and dry conditions over the Gulf Coast. For both seasons the GOGA 


\section{Apr-Sep 1999-2001}

\section{Oct-Mar 1998-2002}

\section{GPCP}
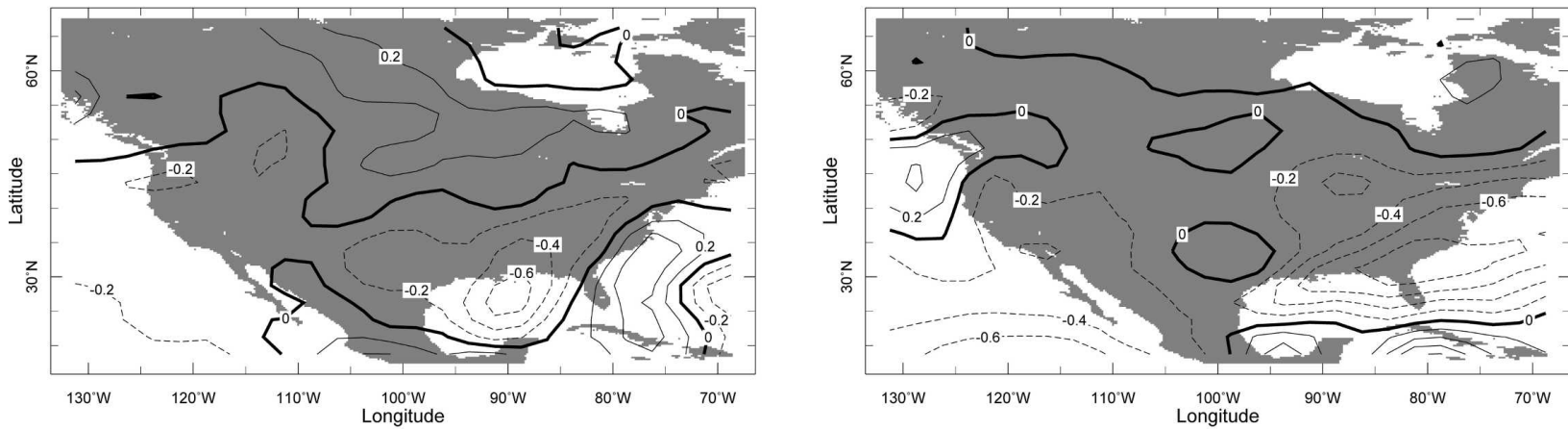

POGA-ML
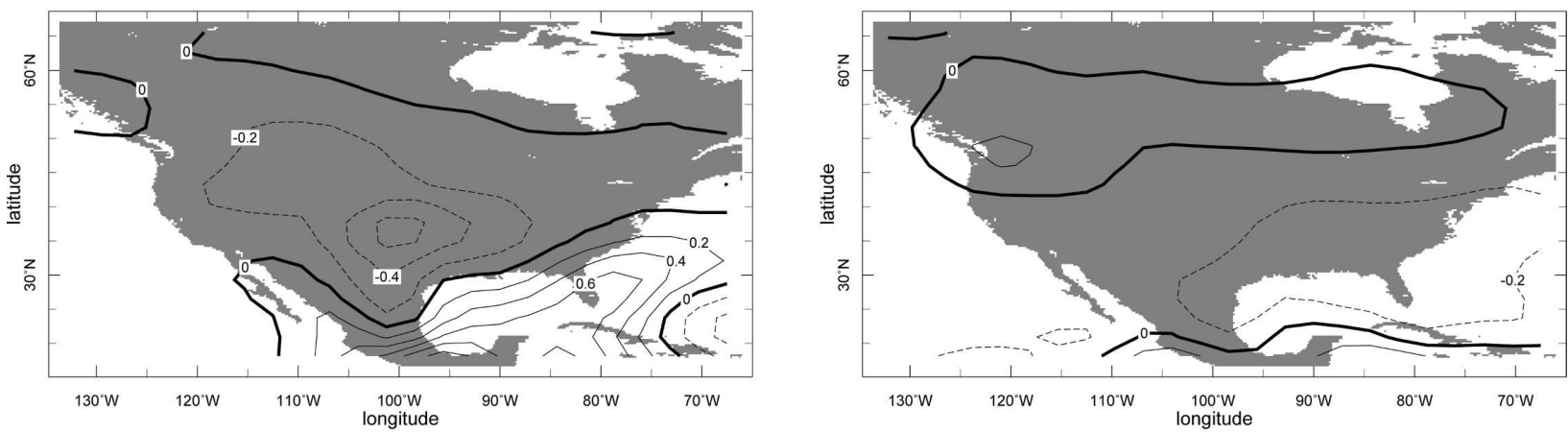

GOGA
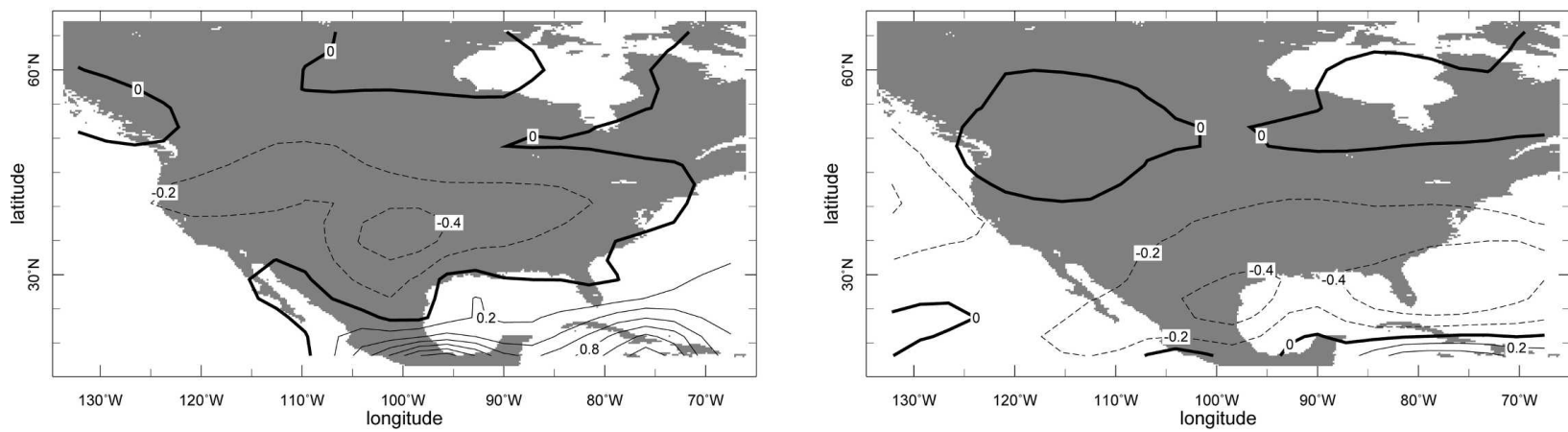

FIG. 14. (top) The observed precipitation anomaly (GPCP) for the (left) summer and (right) winter half years of the 1998-2002 period relative to the 1979-2005 base period, together with that simulated by the (middle) POGA-ML and (bottom) GOGA models. Units are $\mathrm{mm}$ day $^{-1}$.

simulation has a very similar spatial pattern to the POGA-ML model, although the winter anomalies over the Southeast are larger and more realistic in GOGA. The broad similarity of the model and observed precipitation reduction suggests that the model moisture budget may contain useful information about the mechanisms that created the drought. Conclusions based on models alone will remain tentative but are here offered as a testable hypothesis for future confirmation or rejection.

Figure 15 shows the terms in the model vertically integrated moisture budgets for the winter half years of the drought. The mechanisms that sustained the drought were the same in the models with global and tropical Pacific-only SST forcing. Evaporation was reduced across most of the effected region, a conse- 


\section{POGA-ML}

\section{Evaporation}

\section{GOGA}
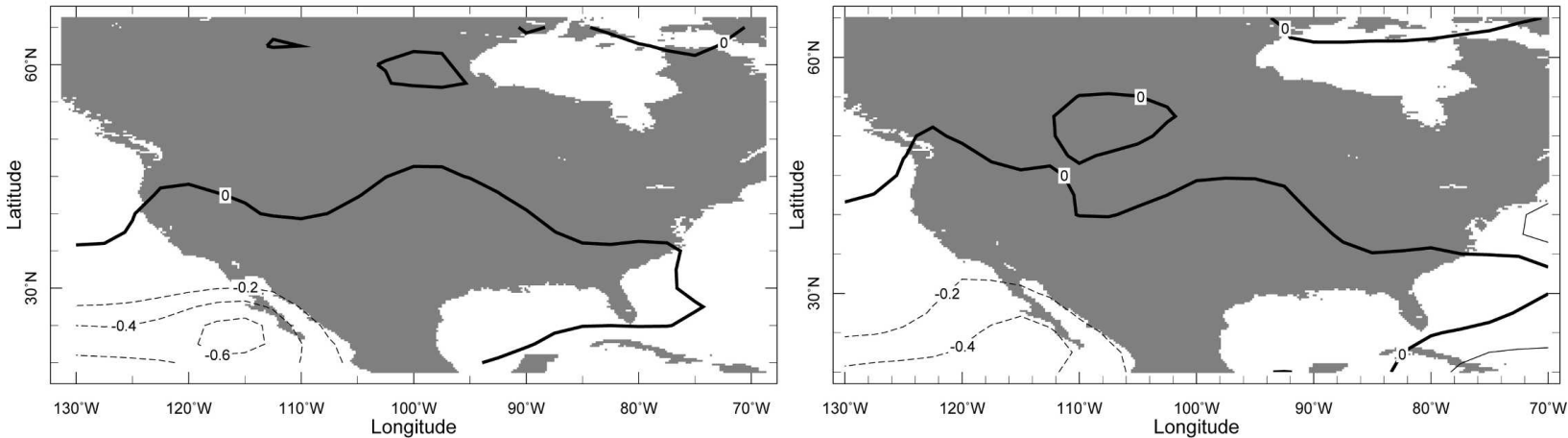

Transient Eddy Conv to $300 \mathrm{mb}$
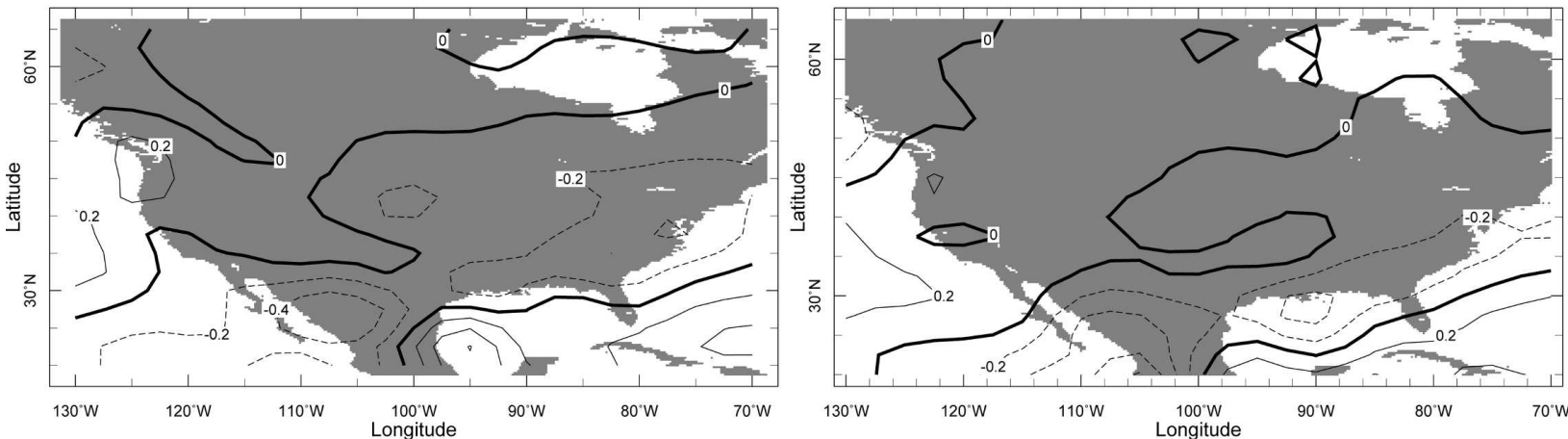

Stationary Flow Conv to $300 \mathrm{mb}$
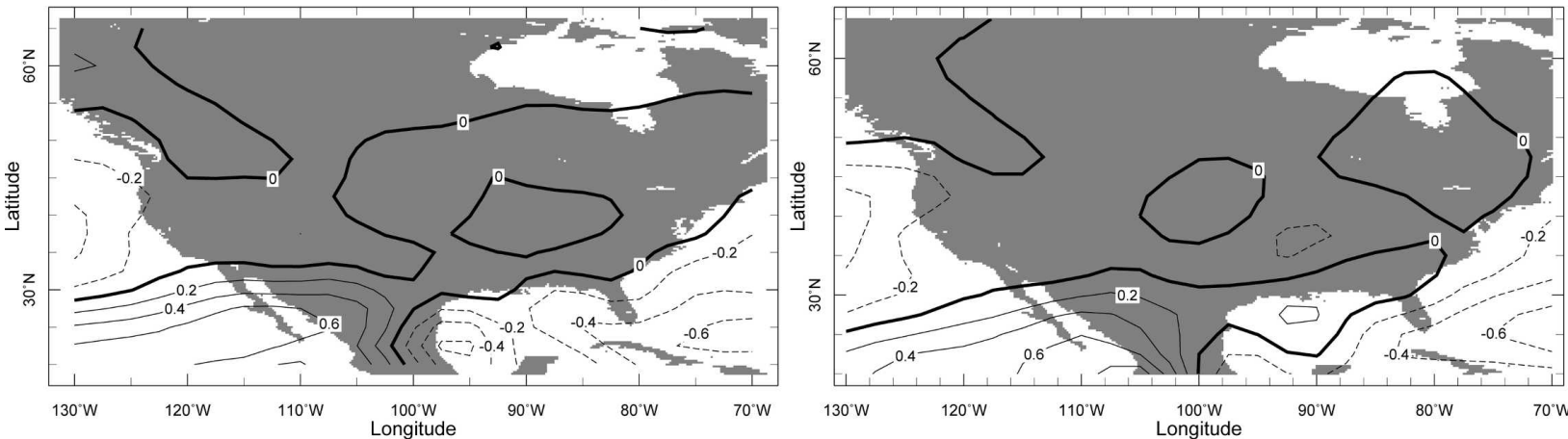

FIG. 15. Terms in the moisture budget of the (left) POGA-ML and (right) GOGA models for the winter half years of the 1998-2002 drought: (top) surface evaporation, (middle) transient eddy moisture convergence, and (bottom) mean flow moisture convergence vertically integrated from the surface to $300 \mathrm{mb}$. Units correspond to $\mathrm{mm} \mathrm{day}^{-1}$ of precipitation.

quence of reduced precipitation. There was reduced transient eddy moisture flux convergence across the far southern United States and northern Mexico, related to weaker eddy activity (as measured by submonthly variance of the meridional wind, not shown) in the subtropics consistent with the tropical tropospheric cooling and reduced baroclinicity in the subtropics (S05a). Reduced moisture convergence by the stationary flow produced a tendency toward reduced precipitation over the east- ern North Pacific and West Coast and over ocean regions south and east of the United States. These results are consistent with those pertaining to interannual variability during northern winter (S05a).

During the summer half years (Fig. 16) the precipitation reduction is concentrated over the continent and is strongly supported by a reduction of surface evaporation. This indicates a role for a soil moisture feedback in extending the drought from the winter half year into 


\section{POGA-ML}

\section{Evaporation}

\section{GOGA}
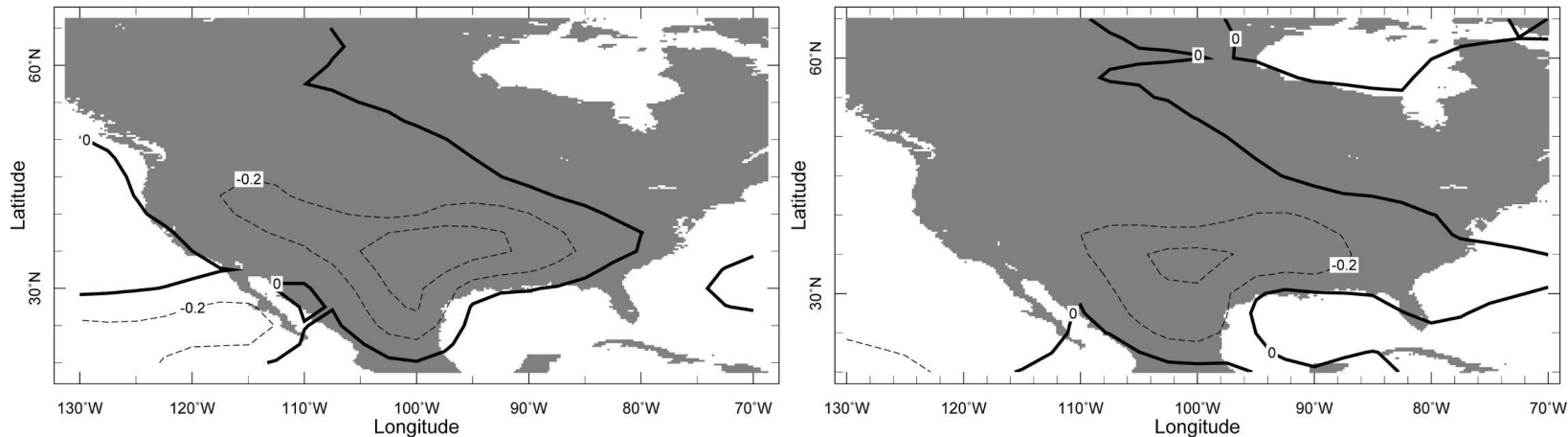

Transient Eddy Conv to $300 \mathrm{mb}$
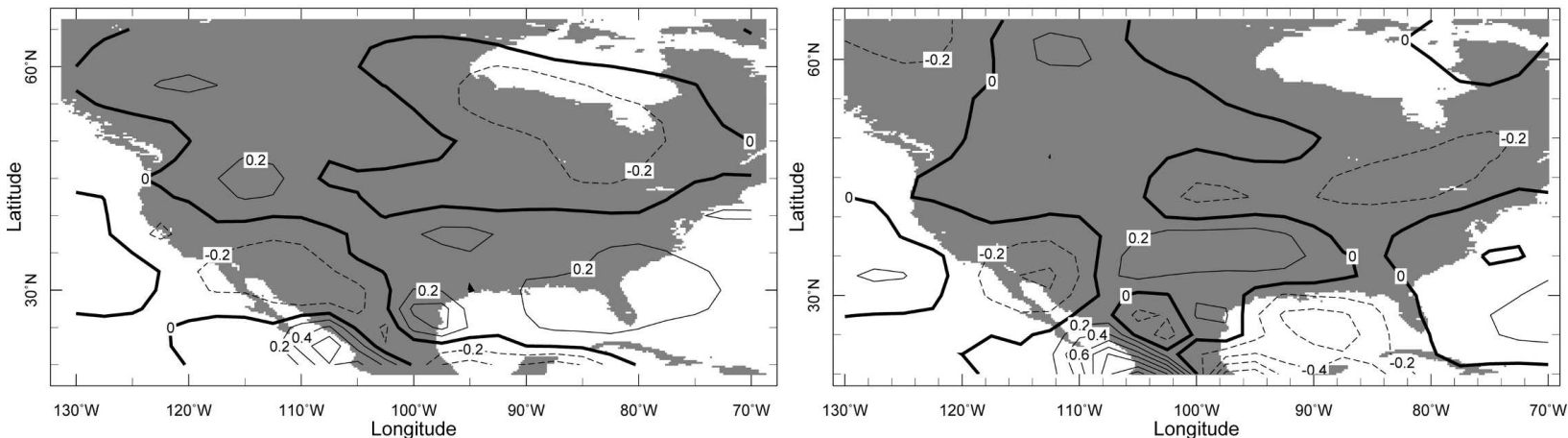

Stationary Flow Conv to $300 \mathrm{mb}$
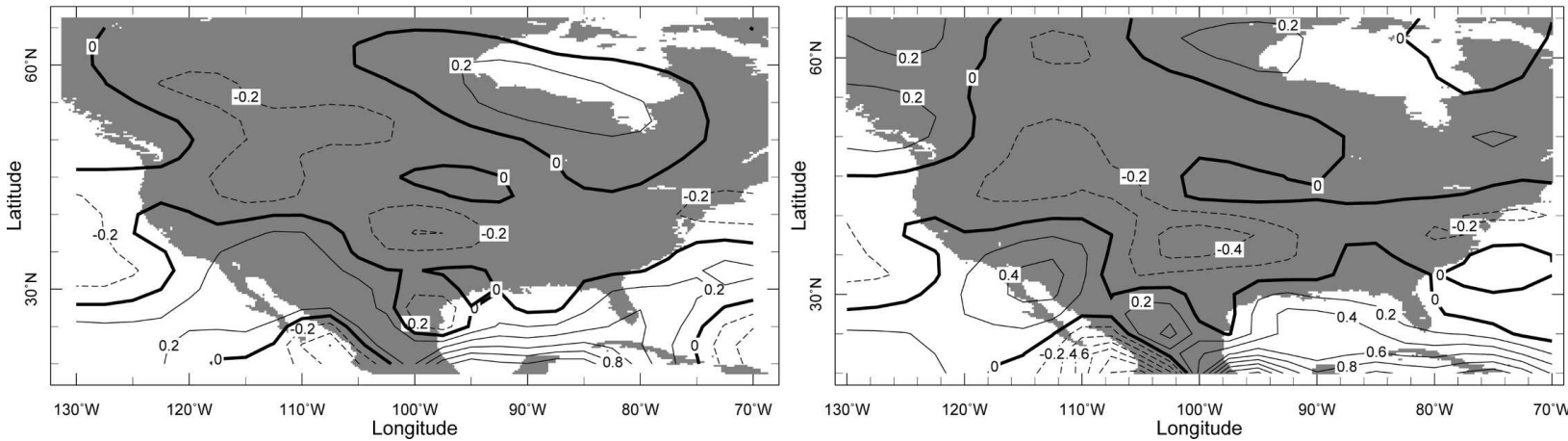

FIG. 16. As in Fig. 15, but for the northern summer half years of the 1998-2002 drought.

the summer half year (S05b and H06 found the same result in studies of earlier droughts). However, this is a model result that cannot be independently verified because of the lack of observational evaporation estimates. It should be noted that Ruiz-Barradas and $\mathrm{Ni}$ gam (2005) found evidence, using land surface models constrained by observed precipitation, that GCMs quite likely overestimate the strength of the summer soil moisture feedback and evaporation variations.

During summers, in addition to the evaporation reduction, changes in the stationary flow convergence also tend to reduce precipitation across the drought region, again consistent with the summers of earlier droughts (S05b). This is opposed by the transient eddy moisture convergence, which acts diffusively by converging anomalous moisture into the drought region. The pattern of anomalous stationary-flow moisture convergence in both seasons is largely accounted for by the change in circulation working on the mean specific humidity field with the mean divergence field being the dominant term [not shown but see Huang et al. (2005)]. 


\section{Apr-Sep 1999-2001 Oct-Mar 1998-2002}

\section{POGA-ML}
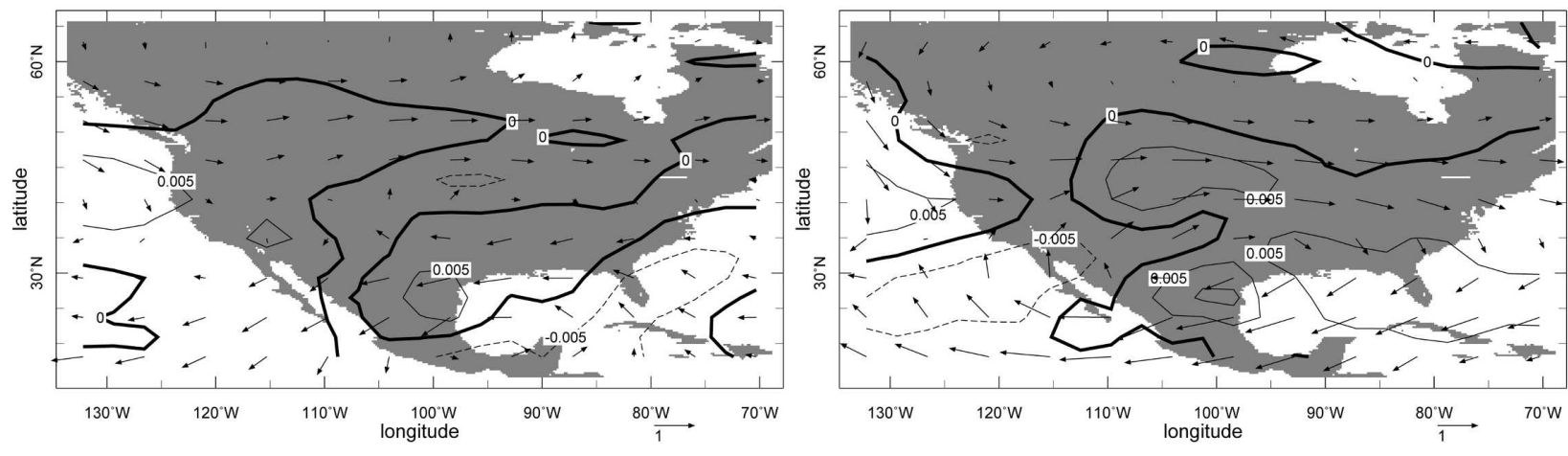

GOGA
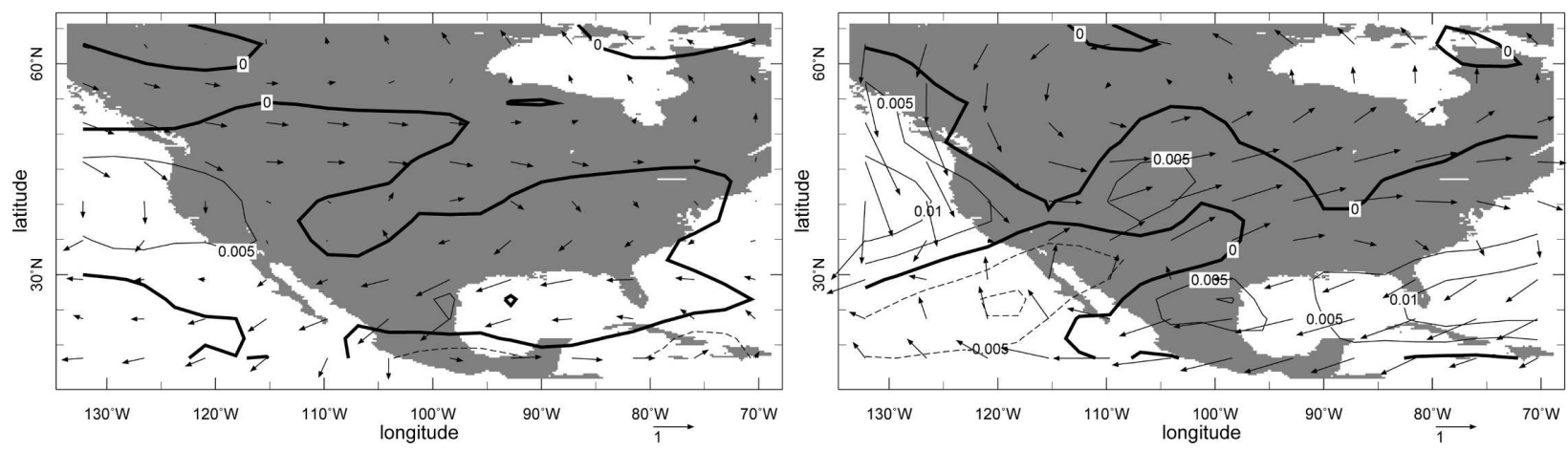

FIG. 17. The anomalies of 700-mb winds (vectors) and vertical pressure velocity at $500 \mathrm{mb}$ (contours) for the northern summer and winter half years of the 1998-2002 period for the (top) POGA-ML model and (bottom) GOGA models. The vector scale is indicated at the bottom right of the panels in $\mathrm{m} \mathrm{s}^{-1}$ and the units for vertical velocity are $\mathrm{Pa} \mathrm{s}^{-1}$.

\section{b. The circulation anomalies associated with the drought}

In Fig. 17 we show the 500-mb vertical pressure velocity anomalies and the 700-mb horizontal flow anomalies for both the POGA-ML and GOGA models for the winter and summer half years of the 1998 to 2002 period of the drought. ${ }^{6}$ Comparing Figs. 14 and 17 we see regions of reduced precipitation in the model (e.g., across the southern United States and northern Mexico in winter) are regions of anomalous subsidence. In the zonal mean it is eddy-induced subsidence that forces the reduction in precipitation. Anomalous subsidence can force regional drying as well, although the dynamics are more complex (S05a).

As in previous studies of persistent droughts over

\footnotetext{
${ }^{6}$ In the reanalysis the subsidence closely follows the derived precipitation, is prone to the same errors, is noisy, hard to explain, and is not shown here.
}

North America (S05b; H06), subsidence is associated with a northerly component to the low-level flow. This is expected from a simple balance between advection of planetary vorticity and vortex stretching, which is most likely to occur during summer (Rodwell and Hoskins 2001), or from a balance between cold advection and subsidence warming, which is more likely in winter. During summer climatological southerly flow over the plains and the Southwest supplies moisture to maintain the summer rains (Higgins et al. 1997; Mo and Berberry 2004). Anomalous northerly flow will reduce the moisture advection. Anomalous northerly flow, subsidence, and low-level divergence are the means whereby the anomalous moisture convergence by the stationary flow helps sustain the reduced precipitation.

\section{c. The signal-to-noise ratio in the SST simulations}

An estimate of the "signal"- the SST-forced precipitation anomaly for 1998-2002 as given by the ensemble mean-to the "noise" is shown in Fig. 18 for the 
a) Winter

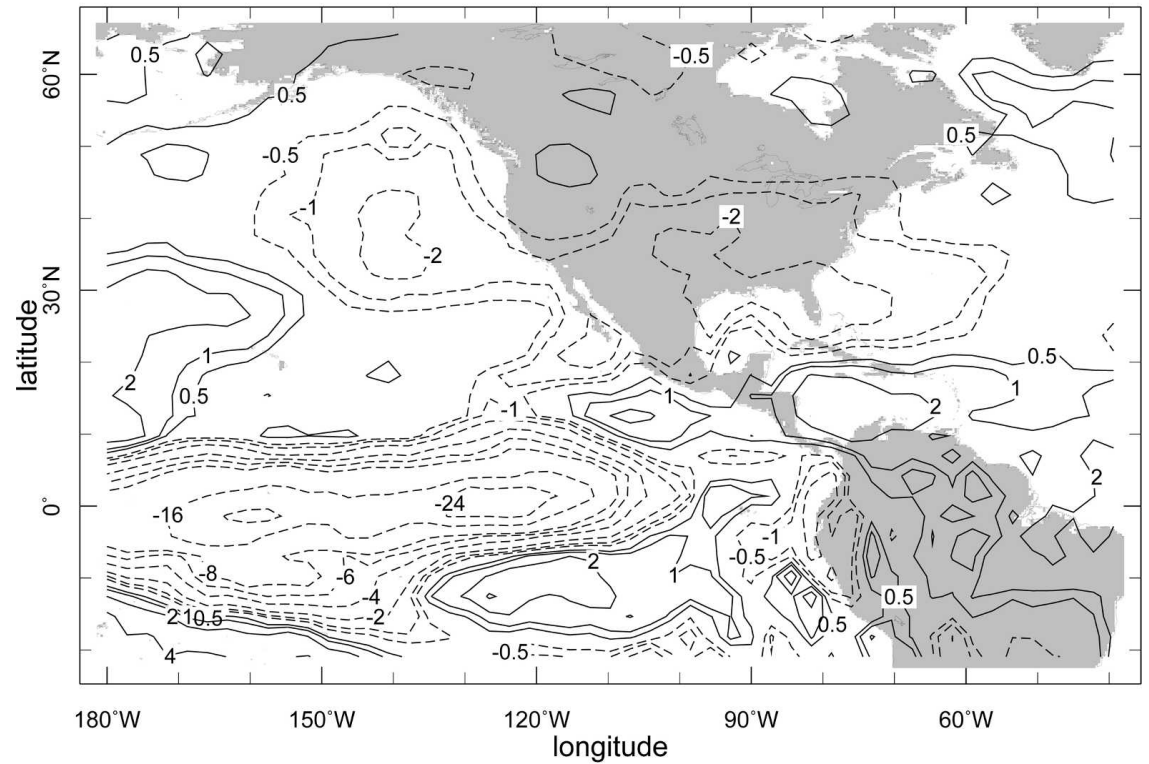

b) Summer

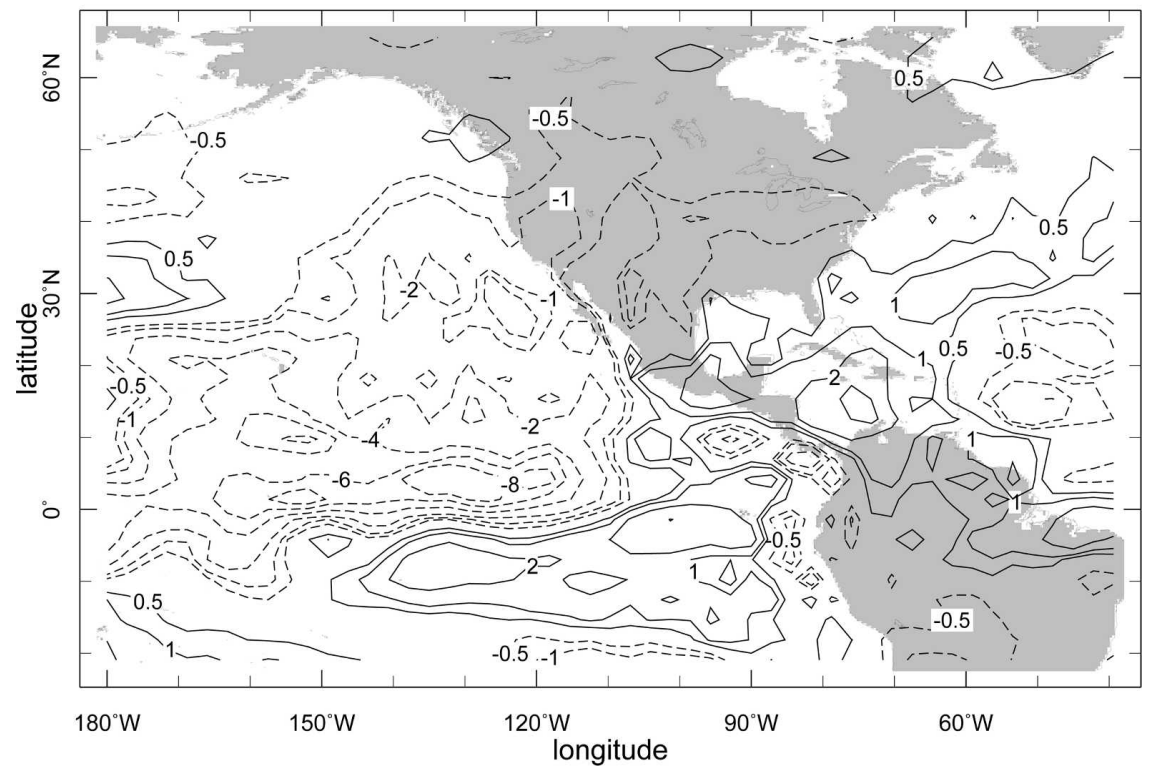

FIG. 18. The ratio of the GOGA ensemble mean precipitation anomaly for the (a) winter and (b) summer half years of the 1998-2002 period to the standard deviation of the spread of the precipitation anomalies of the ensemble members from the ensemble mean. See text for more explanation.

GOGA model. The noise was taken to be the standard deviation of the departures from the ensemble mean of the 1998-2002 precipitation anomalies of the ensemble members. Assuming a Gaussian distribution of precipitation anomalies, a ratio of minus one (minus two) means that the SST-forced precipitation anomaly is the same (twice the) size as the model internal variability and that $84 \%(97 \%)$ of ensemble members have negative precipitation anomalies. During winter half years most of North America has a signal-to-noise ratio above one. During the summer half years the ratio is considerably less, indicating a relatively smaller SSTforced signal, but even so over much of the West twothirds of the ensemble members were dry. 


\section{Comparison of the global context of the turn of the century drought with earlier persistent drought}

It has been suggested that widespread drought in the northern midlatitudes following the 1997-98 El Niño was, in part, associated with the anomalously warm Indian Ocean in combination with a cool tropical Pacific (Hoerling and Kumar 2003; Lau et al. 2006). One way to examine this is to compare the recent drought and its global context with the five prior North American droughts in the instrumental record. These are the Civil War drought of 1856-65, the droughts of the 1870s and 1890s, the Dust Bowl drought, and the 1950s drought (Fye et al. 2003; H06). These periods were identified based on the station precipitation and tree ring records (Cook and Krusic 2004).

In Fig. 19 we plot the near-global SST anomaly from the blended Kaplan and Hadley Centre datasets together with the precipitation anomaly as reported within the GHCN dataset averaged over all months of each of these drought periods. For both SST and precipitation the anomalies are relative to a January 1979 to April 2005 climatology in order to be consistent with figures already presented.

Looking first at the most recent pattern, the Pacific Ocean has a typical La Niña-like pattern but, uncharacteristically for a La Niña, the Indian Ocean was modestly warm. La Niña-like patterns, this time including the expected cool Indian Ocean (Klein et al. 1999; Alexander et al. 2002), were also present in the five prior droughts. The hemispheric symmetry of the SST anomaly fields in all of the droughts adds support to the argument for a tropical source.

As shown in section 3, and argued for by Sutton and Hodson (2005) and Schubert et al. (2004a), there is some modeling evidence that warm tropical Atlantic SSTs tend to create drought over North America. Visually removing the signal of global warming from Fig. 19, it can be seen that, with the exception of the Civil War and 1890s droughts, the northern tropical Atlantic SST anomalies were relatively warm during the droughts. Nonetheless, the Pacific Ocean part of the global SST pattern is consistent drought to drought, suggestive of a strong role for tropical Pacific forcing [in conflict with Sutton and Hodson (2005) who do not mention a role for the Pacific]. No North American drought occurred that was not coincident with a period of sustained La Niña.

Over the Americas there are also similarities between the precipitation pattern of the turn of the century drought and that of prior droughts. Each had dry conditions across the western and central United States and wet conditions in Central America and northern South America. The pattern over North America in the station data during the $1856-65$ and 1870 s droughts is indistinct due to poor data coverage and, perhaps, quality but is clear in the tree ring reconstructions shown in H06 (see also Fye et al. 2003). The hemispheric symmetry also extends to the precipitation record: to the extent that records allow identification, all of the historical North American droughts had a counterpart in midlatitude South America (with the recent drought being a striking exception), once more arguing for a tropical origin to the droughts. In summary, the recent drought looks quite akin to its predecessors in terms of the SST field that forced it and the associated global hydroclimatic pattern (with the exception of midlatitude South America).

\section{Conclusions}

The causes, dynamics, and global context of the recent North American drought, which extended in the West from 1998 to 2004, have been examined using observations, reanalyses, and climate model simulations and in relation to the five prior severe and multiyear droughts that have occurred in the period of instrumental observations of SST (1856 until now). The principal conclusions are as follows.

\section{a. The 1998-2002 period}

The turn of the century drought divides into two distinct periods separated by the summer of 2002. In the earlier period (fall 1998 until spring 2002) the North American drought was associated with a persistent $\mathrm{La}$ Niña and cool tropical Pacific SSTs as in the five prior severe, persistent droughts. Tropical Pacific cooling caused cooling of the tropical troposphere and weakening and poleward movement of the subtropical jet streams and, as a consequence, a poleward displacement of the pattern of poleward flux of zonal momentum by transient eddies. Since in the zonal mean the eddy momentum fluxes are primarily balanced by the Coriolis torque this induces poleward flow in the subtropics and descent in the midlatitudes that suppresses precipitation. The zonal mean anomalies in $P-E$ can largely be accounted for by transport of the mean moisture by the anomalous eddy-driven mean meridional circulation. This mechanism is the same as what occurred in model simulations of earlier droughts (S05b).

Comparison of the simulations conducted with global SST forcing and others conducted with only tropical Pacific SST forcing (and coupled to a mixed layer ocean elsewhere) indicate the primacy of the tropical Pacific forcing. SST anomalies in the tropical Atlantic Ocean play a secondary role. 
a) $1856-1865$

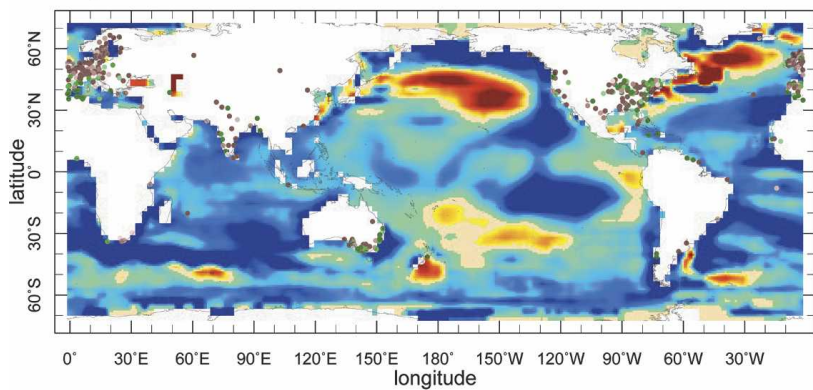

c) $1890-1896$

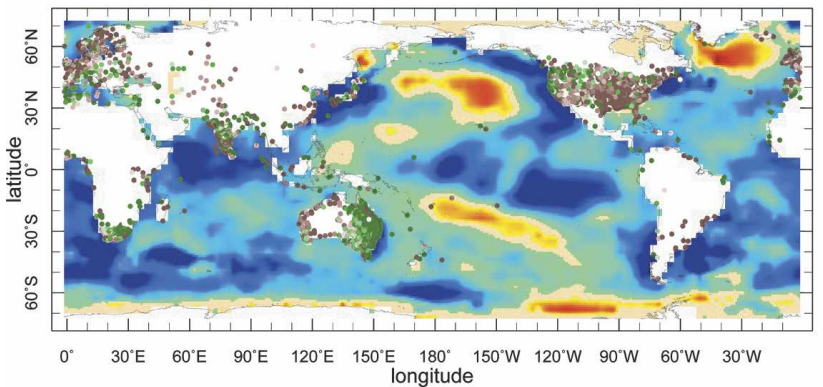

e) $1948-1957$

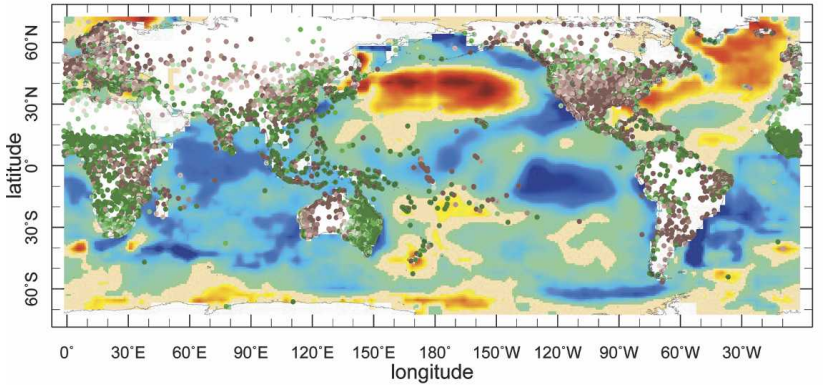

b) $1870-1877$

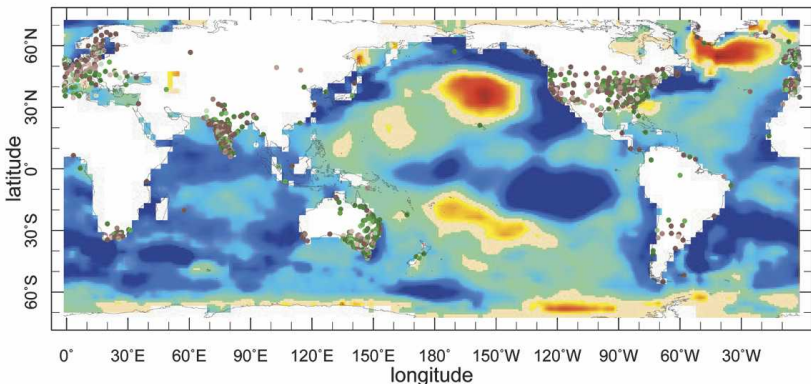

d) 1932-1939

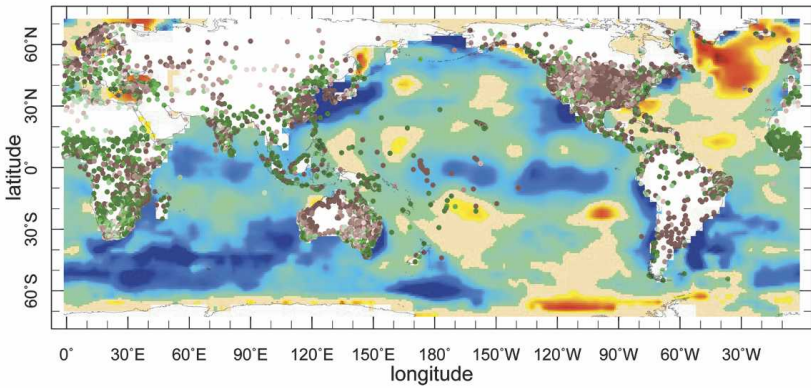

f) $1998-2004$

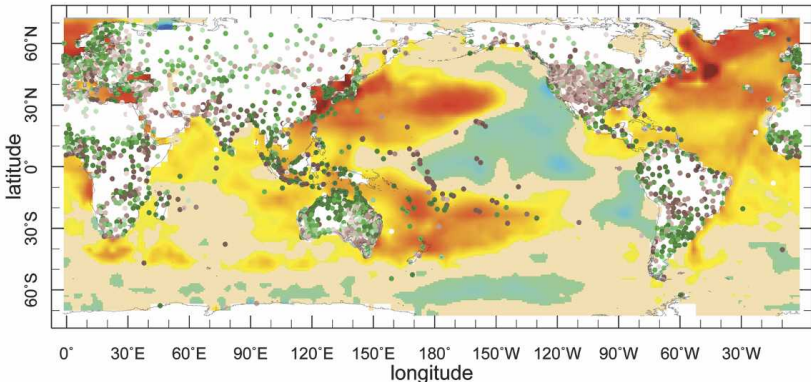

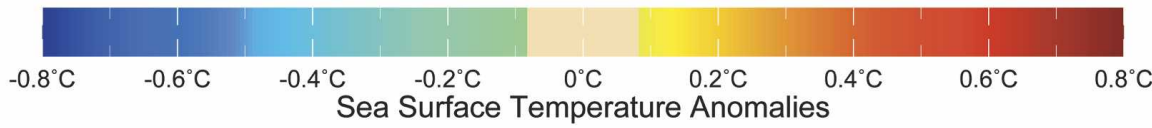

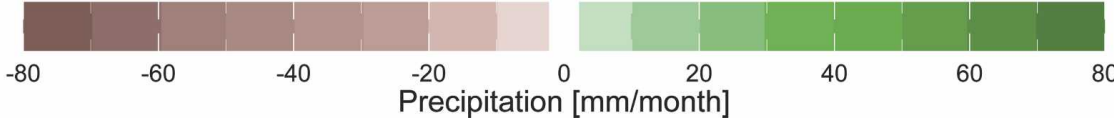

FIG. 19. The SST anomaly and station precipitation anomaly averaged over all seasons of the (a)-(f) six periods of persistent North American drought within the instrumental record. Anomalies are relative to a climatology for the January $1979-$ April 2005 period. Units are $\mathrm{K}$ for SST and $\mathrm{mm}$ month $^{-1}$ for precipitation.

\section{b. The 2002-04 period}

In the later period, summer 2002 through fall 2004, tropical Pacific SSTs became warm as part of a weak El Niño-like state. The global atmosphere circulation anomalies during northern winter then reversed, with stronger, equatorward-shifted subtropical jets, anomalous poleward eddy flux of zonal momentum in the subtropics, induced equatorward flow, and ascent in midlatitudes. The eddy-induced ascent increased precipitation in the midlatitudes of each hemisphere, which is qualitatively captured by the POGA-ML model. Western North America stood out as an exception and the drought of the prior period persisted through 2004.

Basing conclusions on a single model is problematic 
and hence it is of note that, of the other three available ensemble simulations with different GCMs [ECHAM4.5, NCEP, and Seasonal-to-Interannual Prediction Project (NSIPP)] forced by observed SSTs that cover this period, all simulated reduced precipitation after 1998 but ended the drought in 2002. The last two years of the drought therefore appear divorced from the usual global dynamical and atmosphere-ocean context.

\section{c. Mechanisms of drought generation}

In the model the 1998-2002 drought was most closely related to anomalous patterns of subsidence. In the zonal mean the subsidence, and reduction of $P-E$, is induced by transient eddy momentum fluxes. Regionally, over North America, it is enhanced by the stationary wave pattern within which equatorward flow requires descent to balance advection of heat and/or planetary vorticity. In some places and times descent leads directly to low-level moisture divergence by the mean flow, while the equatorward flow also reduces the advection of moisture into North America from the Gulf of Mexico. Both moisture transport processes help sustain drought conditions. During the winter season transient eddies converge less moisture into the region of anomalous mean descent over the southeastern United States and northern Mexico, consistent with tropical cooling and reduced baroclinicity in the subtropics.

\section{d. Prior analogs}

Comparison to prior events makes clear that the 1998-2002 drought was the latest in a series of six persistent global hydroclimate regimes, involving a persistent La Niña-like state in the tropical Pacific and dry conditions across the midlatitudes of each hemisphere, that have occurred since the advent of ocean temperature observations in the mid-nineteenth century. Although the Indian Ocean has steadily warmed over the last half century, this is not implicated as a cause of the turn of the century North American drought because the five prior droughts were associated with cool Indian Ocean SSTs (typical of a La Niña-like state). Since the global hydroclimate regimes of these were very similar to the recent turn of the century regime (except over southern South America), it is concluded that it is the tropical Pacific that plays the dominant role in setting up the global hydroclimate regime.

In conclusion, the 1998-2002 period of the recent drought that has troubled the West was most likely caused by multiyear variability of the tropical Pacific Ocean. This highlights the need to assess whether the tropical Pacific SST variations that force North American droughts are predictable on time scales beyond the interannual (Karspeck et al. 2004; Seager et al. 2004).
The fact that the western drought persisted into 2003 and 2004, even as the tropical Pacific warmed and the global climate adjusted to a more El Niño-like state, and the ensemble mean for the climate model used here (and others) made North America wet indicates that predicability may be limited. That said, the costs of North American droughts and the disruption they cause in agriculture, tourism, forest management, urban water supply, energy generation, etc., are so high that attribution studies such as this should quickly lead into studies of predictability.

Acknowledgments. I thank Yochanan Kushnir, Mingfang Ting, Ed Cook, and Celine Herweijer for useful conversations, Naomi Naik and Gus Correa for performing the model simulations used here, and Jennifer Velez for conducting much of the data analysis. The comments and advice of two anonymous reviewers and Editor, David Strauss, led to considerable improvement in the paper and are gratefully appreciated. This work was supported by NOAA Grants NA030AR4320179 PO7 and 20A and NSF Grants ATM-0347009 and ATM-0501878. The model simulation data can be accessed online at: http://kage.ldeo. columbia.edu:81/expert/SOURCES/.LDEO/. ClimateGroup/.PROJECTS/.CCM3.

\section{APPENDIX}

\section{Calculating $\boldsymbol{P}-\boldsymbol{E}$ Associated with an Eddy-Driven Mean Meridional Circulation}

To calculate the anomalous $\langle\bar{P}\rangle-\langle\bar{E}\rangle$ induced by an anomalous eddy-induced mean meridional circulation we begin by determining the anomalous circulation. The linearized anomaly zonal momentum equation, ignoring all terms except the Coriolis torque and the horizontal transient and stationary eddy momentum flux convergences, is

$$
\begin{aligned}
-\left(f+\frac{\langle\bar{u}}{a} \tan \phi\right)\left\langle\bar{v}_{e, T+S}\right\rangle^{\prime}= & -\frac{1}{a \cos ^{2} \phi} \frac{\partial}{\partial \phi}\left[\left\langle\overline{u^{\prime \prime} v^{\prime \prime}}\right\rangle^{\prime}\right. \\
& \left.+\left\langle\bar{u}^{*} \bar{v}^{*}\right\rangle^{\prime}\right] \cos ^{2} \phi,
\end{aligned}
$$

where $u$ is the zonal and $v_{e, T+S}$ is the transient $(T)$ plus stationary $(S)$ eddy-induced meridional velocity, $f$ is the Coriolis parameter, $\phi$ indicates latitude, $a$ is the radius of the earth, angle brackets indicate zonal means, stars indicate departures from zonal mean, the overbar indicates the monthly mean, double overbars indicate climatological values, primes indicate anomalies of the monthly means, and double primes indicate submonthly transients. Of the neglected terms, for the anomalous circulations considered here, the vertical flux of zonal momentum by transient eddies acts to 
modestly amplify the effects of the horizontal flux, while that by stationary eddies is negligible. Replacing $f$ with the climatological meridional gradient of absolute vorticity led to little difference. The anomaly of zonal momentum advection by the mean vertical flow was important in the deep Tropics away from our primary area of interest.
Since the eddy momentum fluxes are essentially entirely contained within the upper troposphere, Eq. (A1) can be integrated from the top of the boundary layer, $p_{T}$, upward to obtain the eddy-induced meridional free troposphere flow. It is assumed that this is compensated for by a return flow in the boundary layer whose depthaveraged value, $\left\langle\bar{v}_{e B, T+S}\right\rangle^{\prime}$, is given by

$$
\left\langle\bar{v}_{e B, T+S}\right\rangle^{\prime}=-\frac{1}{\left(p_{s}-p_{T}\right) a \cos ^{2} \phi} \int_{0}^{p_{T}}\left(f+\frac{\langle\bar{u}\rangle}{a} \tan \phi\right)^{-1} \frac{\partial}{\partial \phi}\left(\left\langle\overline{u^{\prime \prime} v^{\prime \prime}}\right\rangle^{\prime}+\left\langle\bar{u}^{*} \bar{v}^{*}\right\rangle^{\prime}\right) \cos ^{2} \phi d p .
$$

Here $p_{s}$ is the surface pressure. The eddy-induced boundary layer meridional velocity is assumed to vary linearly from zero at $850 \mathrm{mb}$ to a maximum at the surface, namely,

$$
\left\langle\bar{v}_{e, T+S}\right\rangle^{\prime}=2\left\langle\bar{v}_{e B, T+S}\right\rangle^{\prime} \frac{p-p_{T}}{p_{s}-p_{T}} .
$$

The zonal mean anomaly moisture equation is

$$
\langle\bar{P}\rangle^{\prime}=\langle\bar{E}\rangle^{\prime}-\frac{1}{\rho_{w} g} \int_{0}^{p_{s}}\left(\frac{1}{a \cos \phi} \frac{\partial}{\partial \phi}(\langle\bar{v}\rangle\langle\bar{q}\rangle)^{\prime} \cos \phi\right) d p+\mathrm{TE}^{\prime}+\mathrm{SE}^{\prime}
$$

Here $P$ and $E$ are precipitation and surface evaporation, $\rho_{w}$ is the density of water, $q$ is specific humidity, and TE and SE are the transient and stationary eddy moisture flux convergences. These two tend to oppose each other in the zonal mean (S05a). To isolate changes in $P-E$ due to changes in the MMC, $\left(\langle\bar{P}\rangle-\langle\bar{E}\rangle^{\prime}\right)_{e, \mathrm{MMC}, T+S}$, we next assume that the specific humidity is fixed and replace the flow field with the eddy-induced velocity anomalies given by Eqs. (A1) and (A3):

$$
(\langle\bar{P}\rangle-\langle\bar{E}\rangle)_{e, \mathrm{MMC}, T+S}^{\prime}=-\frac{1}{\rho_{w} g a \cos \phi} \int_{0}^{p_{s}} \frac{\partial}{\partial \phi}\left(\left\langle\overline{\mathbf{v}}_{e, T+S}\right\rangle^{\prime}\langle\overline{\bar{q}}\rangle \cos \phi\right) d p .
$$

The eddy-induced MMC creates an anomaly of $\langle\bar{P}\rangle-$ $\langle\bar{E}\rangle$ that divides into linearly additive contributions from transient and stationary eddy momentum fluxes.

\section{REFERENCES}

Alexander, M. A., I. Blade, M. Newman, J. R. Lanzante, N.-C. Lau, and J. D. Scott, 2002: The atmosphere bridge: The influence of ENSO teleconnections on air-sea interaction over the global ocean. J. Climate, 15, 2205-2231.

Atlas, R., N. Wolfson, and J. Terry, 1993: The effect of SST and soil moisture anomalies on GLA model simulations of the 1998 U.S. summer drought. J. Climate, 6, 2034-2047.

Barlow, M., H. Cullen, and B. Lyon, 2002: Drought in central and southwest Asia: La Niña, the warm pool and Indian Ocean precipitation. J. Climate, 15, 697-700.

Cook, E. R., and P. J. Krusic, 2004: North American summer PDSI reconstructions. IGBP PAGES/World Data Center for Paleoclimatology Data Contribution Series, Tech. Rep. 2004045, NOAA/NCDC Paleoclimatology Program, Boulder, CO.

, R. Seager, M. A. Cane, and D. W. Stahle, 2007: North American droughts: Reconstructions, causes and consequences. Earth-Sci. Rev., 81, 93-134.
Enfield, D. B., A. M. Mestas-Nuñez, and P. J. Trimble, 2001: The Atlantic multidecadal oscillation and its relation to rainfall and river flows in the continental U.S. Geophys. Res. Lett., 28, 2077-2080.

Fye, F. K., D. W. Stahle, and E. R. Cook, 2003: Paleoclimatic analogs to twentieth- century moisture regimes across the United States. Bull. Amer. Meteor. Soc., 84, 901-909.

Garreaud, R. D., and D. S. Battisti, 1999: Interannual (ENSO) and interdecadal (ENSO-like) variability in the Southern Hemisphere tropospheric circulation. J. Climate, 12, 21132123.

Herweijer, C., R. Seager, and E. R. Cook, 2006: North American droughts of the mid to late nineteenth century: History, simulation and implications for Medieval drought. Holocene, 16, 159-171.

Higgins, R. W., Y. Yao, E. S. Yarosh, J. E. Janowiak, and K. C. Mo, 1997: Influence of the Great Plains low-level jet on summertime precipitation and moisture transport over the central United States. J. Climate, 10, 481-507.

Hoerling, M. P., and A. Kumar, 2002: Atmospheric response patterns associated with tropical forcing. J. Climate, 15, 21842203. 
$\longrightarrow$, and - 2003: The perfect ocean for drought. Science, 299, 691-694.

Huang, H., R. Seager, and Y. Kushnir, 2005: The 1976/77 transition in precipitation over the Americas and the influence of tropical SST. Climate Dyn., 24, 721-740.

Huffman, G. J., and Coauthors, 1997: The Global Precipitation Climatology Project (GPCP) Combined Precipitation Dataset. Bull. Amer. Meteor. Soc., 78, 5-20.

Kalnay, E., and Coauthors, 1996: The NCEP/NCAR 40-Year Reanalysis Project. Bull. Amer. Meteor. Soc., 77, 437-471.

Kaplan, A., M. A. Cane, Y. Kushnir, A. C. Clement, M. B. Blumenthal, and B. Rajagopalan, 1998: Analyses of global sea surface temperature: 1856-1991. J. Geophys. Res., 103, 18 567-18 589.

Karspeck, A., R. Seager, and M. A. Cane, 2004: Predictability of tropical Pacific decadal variability in an intermediate model. J. Climate, 17, 2842-2850.

Kiehl, J. T., J. J. Hack, G. B. Bonan, B. A. Bovile, D. L. Williamson, and P. J. Rasch, 1998: The National Center for Atmospheric Research Community Climate Model: CCM3. J. Climate, 11, 1131-1149.

Kistler, R., and Coauthors, 2001: The NCEP-NCAR 50-Year Reanalysis: Monthly means CD-ROM and documentation. Bull. Amer. Meteor. Soc., 82, 247-267.

Klein, S. A., B. J. Soden, and N. Lau, 1999: Remote sea surface temperature variations during ENSO: Evidence for a tropical atmospheric bridge. J. Climate, 12, 917-932.

Kushnir, Y., 1994: Interdecadal variations in North Atlantic sea surface temperature and associated atmospheric conditions. J. Climate, 7, 141-157.

Lau, N.-C., A. Leetmaa, M. J. Nath, and H.-L. Wang, 2005: Influences of ENSO-induced Indo-western Pacific SST anomalies on extratropical atmospheric variability during the boreal summer. J. Climate, 18, 2922-2942.

,-- , and — 2006: Attribution of atmospheric variations in the 1997-2003 period to SST anomalies in the Pacific and Indian Ocean basins. J. Climate, 19, 3607-3628.

Mantua, N. J., S. R. Hare, Y. Zhang, J. M. Wallace, and R. C. Francis, 1997: A Pacific interdecadal climate oscillation with impacts on salmon production. Bull. Amer. Meteor. Soc., 78, 1069-1079.

McCabe, G. J., M. A. Palecki, and J. L. Betancourt, 2004: Pacific and Atlantic influences on multidecadal drought frequency in the United States. Proc. Natl. Acad. Sci. USA, 101, 41364141.

Mo, K. C., and E. H. Berberry, 2004: Low-level jets and the summer precipitation regimes over North America. J. Geophys. Res., 109, D06117, doi:10.1029/2003JD004106.

__ J. R. Zimmerman, E. Kalnay, and M. Kanamitsu, 1991: A GCM study of the 1988 United States drought. Mon. Wea. Rev., 119, 1512-1532.

Newman, M., 2007: Interannual to decadal predictability of tropical and North Pacific sea surface temperatures. J. Climate, 20, 2333-2356.

Rayner, N. A., D. E. Parker, E. B. Horton, C. K. Folland, L. V.
Alexander, D. P. Rowell, E. C. Kent, and A. Kaplan, 2003: Global analyses of sea surface temperature, sea ice, and night marine air temperature since the late nineteenth century. $J$. Geophys. Res., 108, 4407, doi:10.1029/2002JD002670.

Rodwell, M. J., and B. J. Hoskins, 2001: Subtropical anticyclones and summer monsoons. J. Climate, 14, 3192-3211.

Ruiz-Barradas, A., and S. Nigam, 2005: Warm season rainfall variability over the U.S. Great Plains in observations, NCEP and ERA-40 reanalyses, and NCAR and NASA atmospheric model simulations. J. Climate, 18, 1808-1830.

Russell, G. L., J. R. Miller, and L.-C. Tsang, 1985: Seasonal oceanic heat transports computed from an atmospheric model. Dyn. Atmos. Oceans, 9, 253-271.

Schubert, S. D., M. J. Suarez, P. J. Pegion, R. D. Koster, and J. T. Bacmeister, 2004a: Causes of long-term drought in the U.S. Great Plains. J. Climate, 17, 485-503.

,,,,---- and,$- 2004 \mathrm{~b}$ : On the cause of the 1930s Dust Bowl. Science, 303, 1855-1859.

Seager, R., Y. Kushnir, M. Visbeck, N. Naik, J. Miller, G. Krahmann, and H. Cullen, 2000: Causes of Atlantic Ocean climate variability between 1958 and 1998. J. Climate, 13, 2845-2862.

, N. Harnik, Y. Kushnir, W. Robinson, and J. Miller, 2003: Mechanisms of hemispherically symmetric climate variability. J. Climate, 16, 2960-2978.

- A. R. Karspeck, M. A. Cane, Y. Kushnir, A. Giannini, A. Kaplan, B. Kerman, and J. Velez, 2004: Predicting Pacific decadal variability. Earth Climate: The Ocean-Atmosphere Interaction, Geophys. Monogr., Vol. 147, Amer. Geophys. Union, 115-130.

— , N. Harnik, W. A. Robinson, Y. Kushnir, M. Ting, H. P. Huang, and J. Velez, 2005a: Mechanisms of ENSO-forcing of hemispherically symmetric precipitation variability. Quart. J. Roy. Meteor. Soc., 131, 1501-1527.

—, Y. Kushnir, C. Herweijer, N. Naik, and J. Velez, 2005b: Modeling of tropical forcing of persistent droughts and pluvials over western North America: 1856-2000. J. Climate, 18, 4068-4091.

Stahle, D. W., and M. K. Cleaveland, 1988: Texas drought history reconstructed and analyzed from 1698 to 1980. J. Climate, 1, $59-74$.

Sud, Y. C., D. M. Mocko, K. Lau, and R. Atlas, 2003: Simulating the midwestern U.S. drought of 1988 with a GCM. J. Climate, 16, 3946-3965.

Sutton, R. T., and D. L. R. Hodson, 2005: Atlantic Ocean forcing of North American and European summer climate. Science, 309, 115-118.

Trenberth, K., and G. W. Branstator, 1992: Issues in establishing causes of the 1988 drought over North America. J. Climate, 5, $159-172$.

_ and C. J. Guillemot, 1996: Physical processes involved in the 1988 drought and 1993 floods in North America. J. Climate, 9, 1288-1298.

Zhang, Y., J. M. Wallace, and D. S. Battisti, 1997: ENSO-like decade-to-century scale variability: 1900-93. J. Climate, 10, 1004-1020. 